\title{
JOURNAL OF NEUROPHYSIOLOGY
}

\section{VOLUME 71, 1994}

\section{CHIEF EDITOR}

Gordon M. Shepherd

\section{ASSOCIATE EDITORS}

Wayne E. Crill

Nigel W. Daw

Charles D. Gilbert

Charles Liberman

Mark L. Mayer

Allen I. Selverston

Peter L. Strick

\section{EDITORIAL BOARD}

Denis A. Baylor

Robert Burke

David P. Corey

Sol D. Erulkar

Michael Goldberg

Patricia Goldman-Rakic

Ann Graybiel

Ziaul Hasan

Stephen Highstein
Thomas M. Jessell

Kenneth O. Johnson

Daniel Johnston

Robert H. LaMotte

Alan R. Light

Eve E. Marder

A. Robert Martin

Phillip G. Nelson

John G. Nicholls

Roger A. Nicoll

Donata Oertel

Keir G. Pearson

Rami Rahamimoff

Idan Segev

Terrence J. Sejnowski

S. Murray Sherman

Steven A. Siegelbaum

Jun Tanji

Janis Weeks

Frank S. Werblin
PUBLICATIONS COMMITTEE

L. R. Johnson, Chair

D. L. Kunze

L. M. Mendell

L. B. Rowell

J. A. Williams

Ex officio

B. B. Rauner

Publications Manager

and Executive Editor

W. H. Dantzler, President

M. Frank, Executive Director

EDITORIAL STAFF

L. Chambers

Production Manager

J. Adelman

Coordinator 


\title{
Contents of Volume 71
}

\author{
NO. 1. JANUARY 1994
}

Analysis of Voltage-Gated and Synaptic Conductances Contributing to Network Excitability Defects in the Mutant Mouse Tottering

S. A. Helekar and J. L. Noebels

Response of Commissural and Other Upper Cervical Ventral Horn Neurons

to Vestibular Stimuli in Vertical Planes

K. Endo, J. Kasper, V. J. Wilson, and B. J. Yates

Spontaneous Firing Patterns and Axonal Projections of Single Corticostriatal

Neurons in the Rat Medial Agranular Cortex

R. L. Cowan and C. J. Wilson

Discrimination of Direction of Motion in Human Vision

G. Westheimer and C. Wehrhahn

Modulation of Activity in Dorsal Root Ganglion Neurons by Sympathetic Activation in Nerve-Injured Rats

M. Devor, W. Jänig, and M. Michaelis

Block of GABA-Transaminase Modifies GABAergic Transmission at the

Crayfish Synapses

H. Golan and Y. Grossman

Neural Encoding of Single-Formant Stimuli in the Cat. II. Responses of

Anteroventral Cochlear Nucleus Units

$X$. Wang and M. B. Sachs

Adaptive Plasticity of the Auditory Space Map in the Optic Tectum of Adult and Baby Barn Owls in Response to External Ear Modification

E. I. Knudsen, S. D. Esterly, and J. F. Olsen

Neuronal Activity in the Caudolateral Peribrachial Pons: Relationship to PGO

Waves and Rapid Eye Movements

S. Datta and J. A. Hobson

Rhythmic Modulation of the Responsiveness of Locust Sensory Local Interneurons by Walking Pattern Generating Networks

H. Wolf and G. Laurent

Characteristics and Postnatal Development of a Hyperpolarization-Activated Inward Current in Rat Hypoglossal Motoneurons In Vitro

D. A. Bayliss, F. Viana, M. C. Bellingham, and A. J. Berger

Electrophysiological Properties of Guinea Pig Trigeminal Motoneurons Recorded In Vitro

S. H. Chandler, C.-F. Hsaio, T. Inoue, and L. J. Goldberg

Modulatory Influence of Putative Inhibitors of Nitric Oxide Synthesis on Visual Processing in the Cat Lateral Geniculate Nucleus

J. Cudeiro, C. Rivadulla, R. Rodriguez, S. Martinez-Conde, C. Acuña,

and J. M. Alonso

Topographic Patterns of Responsiveness to Odorants in the Rat Olfactory Epithelium

A. Mackay-Sim and S. Kesteven

Tactile Activity in Primate Primary Somatosensory Cortex During Active Arm Movements: Correlation With Receptive Field Properties

D. A. D. Cohen, M. J. L. Prud'Homme, and J. F. Kalaska

Tactile Activity in Primate Primary Somatosensory Cortex During Active Arm Movements: Cytoarchitectonic Distribution

M. J. L. Prud'Homme, D. A. D. Cohen, and J. F. Kalaska

Topographic Representation of Auditory Space in the Superior Colliculus of Adult Ferrets After Monaural Deafening in Infancy 
Autoactive Peptides Act at Three Distinct Receptors to Depolarize the Bag

Cell Neurons of Aplysia

K. J. Loechner and L. K. Kaczmarek

Neonatal Irradiation Prevents the Formation of Hippocampal Mossy Fibers and the

Epileptic Action of Kainate on Rat CA3 Pyramidal Neurons

J.-L. Gaiarsa, L. Zagrean, and Y. Ben-Ari

Repetitive Stimulation Induced Potentiation of Excitatory Transmission in the Rat

Dorsal Horn: An In Vitro Study

S. Jeftinija and L. Urban

Microstimulation of the Medullary Reticular Formation During Fictive Locomotion M.-C. Perreault, S. Rossignol, and T. Drew

Neural Interaction in Cat Primary Auditory Cortex. II. Effects of Sound Stimulation J. J. Eggermont

Variation in $I_{\mathrm{H}}, I_{\mathrm{IR}}$, and $I_{\mathrm{LEAK}}$ Between Acutely Isolated Adult Rat Dorsal Root

Ganglion Neurons of Different Size

R. S. Scroggs, S. M. Todorovic, E. G. Anderson, and A. P. Fox

Spatiotemporally Differential Inhibition of Pyramidal Cells in the Cat Motor Cortex

Y. Kang, T. Kaneko, H. Ohishi, K. Endo, and T. Araki

271

280

Simulator for Neural Networks and Action Potentials: Description and Application I. Ziv, D. A. Baxter, and J. H. Byrne

294

Correlating Resting Discharge With Small Signal Sensitivity and Discharge

Variability in Primary Endings of Cat Soleus Muscle Spindles J. J. A. Scott, J. E. Gregory, U. Proske, and D. L. Morgan

309

Potassium Currents in Mammalian and Avian Isolated Type I Semicircular Canal

Hair Cells

$K$. J. Rennie and M. J. Correia

317

Receptive-Field Maps of Correlated Discharge Between Pairs of Neurons in the

Cat's Visual Cortex

G. M. Ghose, I. Ohzawa, and R. D. Freeman

330

Length and Width Tuning of Neurons in the Cat's Primary Visual Cortex

G. C. DeAngelis, R. D. Freeman, and I. Ohzawa

An Active Membrane Model of the Cerebellar Purkinje Cell. I. Simulation of Current

Clamps in Slice

E. De Schutter and J. M. Bower

375

An Active Membrane Model of the Cerebellar Purkinje Cell. II. Simulation of

Synaptic Responses

E. De Schutter and J. M. Bower

401

Activity Induced Elevations of Intracellular Calcium Concentration in Neurons

of the Deep Cerebellar Nuclei

R. Muri and T. Knöpfel

\section{RAPID PUBLICATIONS}

Cross-Modal Synthesis in the Midbrain Depends on Input From Cortex

M. T. Wallace and B. E. Stein

Multiple High-Threshold Calcium Currents in Acutely Isolated Rat Amygdaloid

Pyramidal Cells

R. C. Foehring and R. S. Scroggs

\section{NO. 2. FEBRUARY 1994}

Efferent Neurons and Suspected Interneurons in Motor Cortex of the Awake Rabbit: Axonal Properties, Sensory Receptive Fields, and Subthreshold Synaptic Inputs

H. A. Swadlow

Modulation of High-Threshold Transmission Between Heart Interneurons of the Medicinal Leech by FMRF-NH 
Functional Characteristics of Spontaneously Active Neurons in Rat Dorsal Cochlear

Nucleus In Vitro

H. J. Waller and D. A. Godfrey

Whole-Cell Analysis of Ionic Currents Underlying the Firing Pattern of Neurons in

the Gustatory Zone of the Nucleus Tractus Solitarii

F. Tell and R. M. Bradley

479

Lateral Suppression and Inhibition in the Cochlear Nucleus of the Cat

W. S. Rhode and S. Greenberg

493

The Role of D1-Dopamine Receptor in Working Memory: Local Injections of

Dopamine Antagonists Into the Prefrontal Cortex of Rhesus Monkeys Performing an Oculomotor Delayed-Response Task

T. Sawaguchi and P. S. Goldman-Rakic

515

The Effect of Phorbol Esters on the Responses of Primate Spinothalamic Neurons to Mechanical and Thermal Stimuli

J. Paleček, V. Palečková, P. M. Dougherty, and W. D. Willis

A Simulation of Action Potentials in Synaptic Boutons During Presynaptic Inhibition

B. Graham and S. Redman

Corticocortical and Thalamocortical Responses of Neurons in the Monkey Primary

Motor Cortex and Their Relation to a Trained Motor Task

H. Aizawa and J. Tanji

Guinea Pig Visceral C-Fiber Neurons Are Diverse With Respect to the $\mathrm{K}^{+}$Currents

Involved in Action-Potential Repolarization

E. P. Christian, J. Togo, and K. E. Naper

Resonant Behavior and Frequency Preferences of Thalamic Neurons

E. Puil, H. Meiri, and Y. Yarom

Low-Threshold Calcium Current and Resonance in Thalamic Neurons: A Model

of Frequency Preference

B. Hutcheon, R. M. Miura, Y. Yarom, and E. Puil

Inositol 1,4,5-Trisphosphate-Gated Conductance in Isolated Rat Olfactory Neurons

Y. Okada, J. H. Teeter, and D. Restrepo

Corrective Responses to Loss of Ground Support During Walking. I. Intact Cats

M. A. Gorassini, A. Prochazka, G. W. Hiebert, and M. J. A. Gauthier

538

Corrective Responses to Loss of Ground Support During Walking. II. Comparison

of Intact and Chronic Spinal Cats

G. W. Hiebert, M. A. Gorassini, W. Jiang, A. Prochazka, and K. G. Pearson

Modeling Three-Dimensional Velocity-to-Position Transformation

in Oculomotor Control

C. Schnabolk and T. Raphan

Large Amplitude Variability of GABAergic IPSCs in Melanotropes From Xenopus laevis: Evidence That Quantal Size Differs Between Synapses

J. G. G. Borst, J. C. Lodder, and K. S. Kits

Ionic Conductances of Monkey Solitary Cone Inner Segments

T. Yagi and P. R. Macleish

Comparative Transduction Mechanisms of Hair Cells in the Bullfrog Utriculus

I. Responses to Intracellular Current

R. A. Baird

Comparative Transduction Mechanisms of Hair Cells in the Bullfrog Utriculus

II. Sensitivity and Response Dynamics to Hair Bundle Displacement

R. A. Baird

Interaction of Excitation and Inhibition in Processing of Pure Tone and AmplitudeModulated Stimuli in the Medial Superior Olive of the Mustached Bat

B. Grothe

Distribution of Static $\gamma$ Axons in Cat Peroneus Tertius Spindles Determined by Exclusively Physiological Criteria

J. Celichowski, F. Emonet-Dénand, Y. Laporte, and J. Petit 
Calcium Currents in Turtle Retinal Ganglion Cells. I. The Properties of T- and

L-Type Currents

$Y$. Liu and E. M. Lasater

Calcium Currents in Turtle Retinal Ganglion Cells. II. Dopamine Modulation via

a Cyclic AMP-Dependent Mechanism

$Y$. Liu and E. M. Lasater

743

Dynamic Exercise Stimulates Group III Muscle Afferents

J. G. Pickar, J. M. Hill, and M. P. Kaufman

753

Glycine Exerts Potent Inhibitory Actions on Mammalian Olfactory Bulb Neurons

P. Q. Trombley and G. M. Shepherd

Processing of Amplitude-Modulated Signals That Mimic Echoes From Fluttering

Targets in the Inferior Colliculus of the Little Brown Bat, Myotis lucifugus

C. J. Condon, K. R. White, and A. S. Feng

768

Monaural and Binaural Spectrum Level Cues in the Ferret: Acoustics and the Neural

Representation of Auditory Space

S. Carlile and A. J. King

Positron Emission Tomographic Analysis of Cerebral Structures Activated

Specifically by Repetitive Noxious Heat Stimuli

K. L. Casey, S. Minoshima, K. L. Berger, R. A. Koeppe, T. J. Morrow, and K. A. Frey

802

\section{RAPID PUBLICATIONS}

Calcium Imaging Reveals Nicotinic Acetylcholine Receptors on Cultured Mushroom

Body Neurons

G. Bicker and S. Kreissl

808

Spatial/Temporal Characteristics of a Motor Pattern for Reaching

M. Flanders, J. J. Pellegrini, and J. F. Soechting

GTP Modulates Run-Up of Whole-Cell $\mathrm{Ca}^{2+}$ Channel Current in a

$\mathrm{Ca}^{2+}$-Dependent Manner

J. J. Wagner and B. E. Alger

814

Reinnervated Muscles Fail to Produce Stretch Reflexes

T. C. Cope, S. J. Bonasera, and T. R. Nichols

Face Recognition in Human Extrastriate Cortex

T. Allison, H. Ginter, G. McCarthy, A. C. Nobre, A. Puce, M. Luby,

and D. D. Spencer

821

Electrophysiological Evidence For Presynaptic Nicotinic Receptors in the Avian

Ventral Lateral Geniculate Nucleus

L. L. McMahon, K.-W. Yoon, and V. A. Chiappinelli

NO. 3. MARCH 1994

Variant Firing Patterns in Rat Hippocampal Pyramidal Cells Modulated by

Extracellular Potassium

M. S. Jensen, R. Azouz, and Y. Yaari

831

Single-Channel Properties of High- and Low-Voltage-Activated Calcium Channels

in Rat Pituitary Melanotropic Cells

J. A. Keja and K. S. Kits

840

Neuronal Selectivities to Complex Object Features in the Ventral Visual Pathway

of the Macaque Cerebral Cortex

E. Kobatake and K. Tanaka

ATP-Induced Inward Current in Neurons Freshly Dissociated From the

Tuberomammillary Nucleus

K. Furukawa, H. Ishibashi, and N. Akaike

In Vivo Measurement of Human Wrist Extensor Muscle Sarcomere Length Changes

R. L. Lieber, G. J. Loren, and J. Fridén 
Defense Reaction in the Pond Snail Planorbis corneus. I. Activity of the

Shell-Moving and Respiratory Systems

Y. I. Arshavsky, T. G. Deliagina, I. L. Okshtein, G. N. Orlovsky,

$Y$. V. Panchin, and L. B. Popova

Defense Reaction in the Pond Snail Planorbis corneus. II. Central Pattern Generator

Y. I. Arshavsky, T. G. Deliagina, I. L. Okshtein, G. N. Orlovsky,

$Y$. V. Panchin, and L. B. Popova

Defense Reaction in the Pond Snail Planorbis corneus. III. Response to Input

From Statocysts

Y. I. Arshavsky, T. G. Deliagina, I. L. Okshtein, G. N. Orlovsky,

Y. V. Panchin, and L. B. Popova

Binaural Organization of Primary Auditory Cortex in the Ferret (Mustela putorius)

J. B. Kelly and P. W. Judge

904

Neuronal Circuits Associated With the Output of the Dorsal Cochlear Nucleus

Through Fusiform Cells

$S$. Zhang and D. Oertel

914

Changes in a Postural Strategy with Inter-Paw Distance

J. M. Macpherson

931

Regulation of Cutaneous C-Fiber Heat Nociceptors by Nerve Growth Factor

in the Developing Rat

G. R. Lewin and L. M. Mendell

941

Monosynaptic and Disynaptic Connections in the Utriculo-Ocular Reflex Arc

of the Cat

Y. Uchino, H. Ikegami, M. Sasaki, K. Endo, M. Imagawa, and N. Isu

950

Spinothalamic and Spinohypothalamic Tract Neurons in the Cervical Enlargement of Rats. I. Locations of Antidromically Identified Axons in the Thalamus and Hypothalamus

R. J. Dado, J. T. Katter, and G. J. Giesler, Jr.

Spinothalamic and Spinohypothalamic Tract Neurons in the Cervical Enlargement of Rats. II. Responses to Innocuous and Noxious Mechanical and Thermal Stimuli

R. J. Dado, J. T. Katter, and G. J. Giesler, Jr.

Spinothalamic and Spinohypothalamic Tract Neurons in the Cervical Enlargement of Rats. III. Locations of Antidromically Identified Axons in the Cervical Cord

White Matter

R. J. Dado, J. T. Katter, and G. J. Giesler, Jr.

Enhancement of Neural Synchronization in the Anteroventral Cochlear Nucleus

I. Responses to Tones at the Characteristic Frequency

P. X. Joris, L. H. Carney, P. H. Smith, and T. C. T. Yin

Enhancement of Neural Synchronization in the Anteroventral Cochlear Nucleus

II. Responses in the Tuning Curve Tail

P. X. Joris, P. H. Smith, and T. C. T. Yin

Functional Properties of Rat and Human Neocortical Voltage-Sensitive

Sodium Currents

T. R. Cummins, Y. Xia, and G. G. Haddad

1052

A Model For Dendritic $\mathrm{Ca}^{2+}$ Accumulation in Hippocampal Pyramidal Neurons

Based on Fluorescence Imaging Measurements

D. B. Jaffe, W. N. Ross, J. E. Lisman, N. Lasser-Ross, H. Miyakawa,

and D. Johnston

1065

Sound Localization After Unilateral Lesions of Inferior Colliculus in the Ferret (Mustela putorius)

J. B. Kelly and G. L. Kavanagh

1078

Presynaptic Inhibition is Mediated by Histamine and GABA in the Crustacean

Escape Reaction

A. El Manira and F. Clarac 
Mechanical Actions of Heterogenic Reflexes Linking Long Toe Flexors With Ankle and Knee Extensors of the Cat Hindlimb

S. J. Bonasera and T. R. Nichols

Characteristics of Antidromically Identified Oculomotor Internuclear Neurons

During Vergence and Versional Eye Movements

R. A. Clendaniel and L. E. Mays

1111

Mechanism of Early Anoxia-Induced Suppression of the $\mathrm{GABA}_{\mathrm{A}}-$ Mediated

Inhibitory Postsynaptic Current

A. N. Katchman, S. Vicini, and N. Hershkowitz

1128

Noradrenaline Mediates Paradoxical Effects on Rat Neocortical Neurons After

GABA Withdrawal

C. Silva-Barrat, J. Champagnat, J. Leiva, and V. Pavlik

1139

Differential Effects of Muscimol Microinjection Into Dorsal and Ventral Aspects

of the Premotor Cortex of Monkeys

K. Kurata and D. S. Hoffman

1151

Effects of Anoxia on Rat Midbrain Dopamine Neurons

N. B. Mercuri, A. Bonci, S. W. Johnson, F. Stratta, P. Calabresi, and $G$. Bernardi

Contribution of a Slowly Inactivating Potassium Current to the Transition to Firing of Neostriatal Spiny Projection Neurons

E. S. Nisenbaum, Z. C. Xu, and C. J. Wilson

$\mathrm{Ca}^{2+}$-Dependent Non-NMDA Receptor-Mediated Synaptic Currents in Ischemic

CA1 Hippocampal Neurons

H. Tsubokawa, K. Oguro, T. Masuzawa, and N. Kawai

Spontaneous and Transmitter-Induced Rhythmic Activity in Neonatal Rat

Sympathetic Preganglionic Neurons In Vitro

E. Shen, S. Y. Wu, and N. J. Dun

Visual Response Properties of Single Neurons in the Temporal Pole of

Behaving Monkeys

K. Nakamura, K. Matsumoto, A. Mikami, and K. Kubota

1206

Inertial Representation of Angular Motion in the Vestibular System of Rhesus

Monkeys. I. Vestibuloocular Reflex

D. E. Angelaki and B. J. M. Hess

\section{RAPID PUBLICATIONS}

Frontal Eye Field Activity Preceding Aurally Guided Saccades

G. S. Russo and C. J. Bruce

1250

Transient Changes in Intracellular Calcium Associated With a Prolonged Increase in Excitability in Neurons of Aplysia californica

T. E. Fisher, S. Levy, and L. K. Kaczmarek

Dopamine Modulation of $\mathrm{GABA}_{\mathrm{C}}$ Receptor Function in an Isolated Retinal Neuron C.-J. Dong and F. S. Werblin

Task Dependent Patterns of Muscle Activation at the Shoulder and Elbow for Unconstrained Arm Movements D.-A. Hong, D. M. Corcos, and G. L. Gottlieb

Primate Frontal Eye Field Activity During Natural Scanning Eye Movements D. D. Burman and M. A. Segraves

Acutely Isolated Neurons of the Rat Globus Pallidus Exhibit Four Types

of High-Voltage-Activated $\mathrm{Ca}^{2+}$ Current

D. J. Surmeier, N. Seno, and S. T. Kitai

Modulation of Preparatory Neuronal Activity in Dorsal Premotor Cortex due to Stimulus-Response Compatibility

D. J. Crammond and J. F. Kalaska

Eye Movements Modulate Activity in Hippocampal, Parahippocampal, and Inferotemporal Neurons

J. L. Ringo, S. Sobotka, M. D. Diltz, and C. M. Bunce 
Physiological Properties of Anatomically Identified Axo-Axonic Cells

in the Rat Hippocampus

E. H. Buhl, Z.-S. Han, Z. Lörinczi, V. V. Stezhka, S. V. Karnup, and P. Somogyi

1289

Hyperpolarization-Activated Currents, $I_{\mathrm{H}}$ and $I_{\mathrm{KIR}}$, in Rat Dorsal Motor Nucleus

of the Vagus Neurons In Vitro

R. A. Travagli and R. A. Gillis

1308

Noise Analysis of Miniature IPSCs in Adult Rat Brain Slices: Properties and



Y. De Koninck and I. Mody

1318

Climbing Fiber Responses of Purkinje Cells to Retinal Image Movement in Cat

Cerebellar Flocculus

H. Fushiki, Y. Sato, A. Miura, and T. Kawasaki

1336

Mode of Firing and Rectifying Properties of Nucleus Ovoidalis Neurons in the Avian

Auditory Thalamus

B. Ströhmann, D. W. F. Schwarz, and E. Puil

1351

Subthreshold Frequency Selectivity in Avian Auditory Thalamus

B. Ströhmann, D. W. F. Schwarz, and E. Puil

Responses of Single Hamster Parabrachial Neurons to Binary Taste Mixtures

of $\mathrm{NaCl}$ with Sucrose or $\mathrm{QHCl}$

M. B. Vogt and D. V. Smith

The Regulation of Chloride Homeostasis in the Small Nonspiking Visual

Interneurons of the Fly Compound Eye

R. O. Uusitalo and M. Weckström

A Control Strategy for the Execution of Explosive Movements From Varying

Starting Positions

A. J. Van Soest, M. F. Bobbert, and G. J. Van Ingen Schenau

Temporal Covariance of Pre- and Postsynaptic Activity Regulates Functional

Connectivity in the Visual Cortex

Y. Frégnac, J. P. Burke, D. Smith, and M. J. Friedlander

1403

Intracellular Characterization of Identified Sensory Cells in a New Spider

Mechanoreceptor Preparation

E.-A. Seyfarth and A. S. French

Activity of Inferior Temporal Neurons During Orientation Discrimination

With Successively Presented Gratings

R. Vogels and G. A. Orban

Effects of Chronic Spinalization on Ankle Extensor Motoneurons. I. Composite

Monosynaptic Ia EPSPs in Four Motoneuron Pools

S. Hochman and D. A. McCrea

Effects of Chronic Spinalization on Ankle Extensor Motoneurons. II. Motoneuron

Electrical Properties

S. Hochman and D. A. McCrea

Effects of Chronic Spinalization on Ankle Extensor Motoneurons. III. Composite Ia EPSPs in Motoneurons Separated Into Motor Unit Types

S. Hochman and D. A. McCrea

Mammalian Voltage-Activated Calcium Channel Currents Are Blocked by $\mathrm{Pb}^{2+}$, $\mathrm{Zn}^{2+}$, and $\mathrm{Al}^{3+}$

D. Büsselberg, B. Platt, D. Michael, D. O. Carpenter, and H. L. Haas

Physiological Properties and Somatotopic Organization of the Primate

Motor Thalamus

J. L. Vitek, J. Ashe, M. R. DeLong, and G. E. Alexander

Compartmentalization of Pattern-Initiation and Motor Functions in the B31 and B32 Neurons of the Buccal Ganglia of Aplysia californica

I. Hurwitz, R. S. Goldstein, and A. J. Susswein 
Control of Jaw Orientation and Position in Mastication and Speech

D. J. Ostry and K. G. Munhall

1528

Muscle Activation Patterns for Reaching: The Representation of Distance and Time

C. A. Buneo, J. F. Soechting, and M. Flanders

1546

Motion Sensitivity in the Nucleus of the Basal Optic Root of the Pigeon

$F$. Wolf-Oberhollenzer and K. Kirschfeld

1559

Spontaneous Interictal-Like Activity Originates in Multiple Areas of the CA2-CA3

Region of Hippocampal Slices

L. V. Colom and P. Saggau

1574

\section{RAPID PUBLICATIONS}

Weak Excitation and Simultaneous Inhibition Induce Long-Term Depression

in Hippocampal CA1 Neurons

X.-D. Yang, J. A. Connor, and D. S. Faber

1586

Ascorbic Acid, but not Glutathione, Is Taken Up by Brain Slices and Preserves

Cell Morphology

M. E. Rice, M. A. Pérez-Pinzón, and E. J. K. Lee

\section{NO. 5. MAY 1994}

Responses of Macaque STS Neurons to Optic Flow Components: A Comparison of Areas MT and MST

L. Lagae, H. Maes, S. Raiguel, D.-K. Xiao, and G. A. Orban

Delayed Depolarization and Slow Sodium Currents in Cutaneous Afferents

O. Honmou, D. A. Utzschneider, M. A. Rizzo, C. M. Bowe, S. G. Waxman, and J. D. Kocsis

Dependence of LTP Induction on Postsynaptic Depolarization: A Perforated

Patch-Clamp Study in Visual Cortical Slices of Young Rats

Y. Yoshimura and T. Tsumoto

The Parabrachial Area: Electrophysiological Evidence for an Involvement

in Visceral Nociceptive Processes

J. F. Bernard, G. F. Huang, and J. M. Besson

1646

Modulation of Transient Outward Potassium Current by GTP, Calcium, and

Glutamate in Horizontal Cells of the Xenopus Retina

A. Akopian and P. Witkovsky

Orientation-Sensitive Amacrine and Ganglion Cells in the Rabbit Retina

S. A. Bloomfield

Gustatory Neural Coding in the Monkey Cortex: The Quality of Saltiness

T. R. Scott, C. R. Plata-Salamán, and V. L. Smith-Swintosky

The Role of GABA-Mediated Inhibition in the Rat Ventral Posterior Medial

Thalamus. I. Assessment of Receptive Field Changes Following Thalamic

Reticular Nucleus Lesions

S. M. Lee, M. H. Friedberg, and F. F. Ebner

1702

The Role of GABA-Mediated Inhibition in the Rat Ventral Posterior Medial Thalamus. II. Differential Effects of $\mathrm{GABA}_{A}$ and $\mathrm{GABA}_{\mathrm{B}}$ Receptor Antagonists on Responses of VPM Neurons

S. M. Lee, M. H. Friedberg, and F. F. Ebner

Computer Simulations of the Effects of Different Synaptic Input Systems on the Steady-State Input-Output Structure of the Motoneuron Pool

C. J. Heckman

Influence of Callosal Activity on Units in the Auditory Cortex of Ferret

(Mustela putorius)

L. M. Kitzes and D. Doherty

A Novel Long-Latency Response of Locus Coeruleus Neurons to Noxious Stimuli:

Mediation by Peripheral C-fibers

H. Hirata and G. Aston-Jones 
Chronic Neocortical Epileptogenesis In Vitro

S. N. Hoffman, P. A. Salin, and D. A. Prince

1762

The Electrotonic Structure of Regular-Spiking Neurons in the Ventral Cochlear

Nucleus May Determine Their Response Properties

J. A. White, E. D. Young, and P. B. Manis

1774

Transmembrane Ion Movements Elicited by Sodium Pump Inhibition

in Helix aspersa Neurons

F. J. Alvarez-Leefmans, H. Cruzblanca, S. M. Gamiño, J. Altamirano,

A. Nani, and L. Reuss

1787

Encoding of Amplitude Modulation in the Cochlear Nucleus of the Cat

$W$. S. Rhode and S. Greenberg

1797

The Antidromic Compound Action Potential of the Auditory Nerve

M. C. Brown

1826

Antidromic Responses of Single Units From the Spiral Ganglion

M. C. Brown

1835

Proprioceptive Coordination of Movement Sequences: Role of Velocity and

Position Information

P. Cordo, L. Carlton, L. Bevan, M. Carlton, and G. K. Kerr

1848

Proprioceptive Coordination of Movement Sequences: Discrimination of Joint Angle

Versus Angular Distance

L. Bevan, P. Cordo, L. Carlton, and M. Carlton

1862

Opening of Large-Conductance Calcium-Activated Potassium Channels by the

Substituted Benzimidazolone NS004

M. C. McKay, S. I. Dworetzky, N. A. Meanwell, S.-P. Olesen, P. H. Reinhart,

I. B. Levitan, J. P. Adelman, and V. K. Gribkoff

1873

Compartmental Modeling of Rat Macular Primary Afferents From Three-

Dimensional Reconstructions of Transmission Electron Micrographs

of Serial Sections

T. C. Chimento, D. G. Doshay, and M. D. Ross

1883

The Reflex Effects of Nonnoxious Sural Nerve Stimulation on Human Triceps

Surae Motor Neurons

C. G. Kukulka

Influence of Stimulus Level on Acoustic Motion-Direction Sensitivity in Barn

Owl Midbrain Neurons

H. Wagner, T. Trinath, and D. Kautz

1907

Dye Coupling Between Rat Striatal Neurons Recorded In Vivo: Compartmental

Organization and Modulation by Dopamine

S.-P. Onn and A. A. Grace

Distribution and Functional Properties of 5- $\mathrm{HT}_{3}$ Receptors in the Rat Hippocampal

Dentate Gyrus: A Patch-Clamp Study

K. Kawa

1935

Electrotonic Profiles of Interneurons in Stratum Pyramidale of the CA1 Region

of Rat Hippocampus

D. Thurbon, A. Field, and S. Redman

1948

Processing of Frequency-Modulated Sounds in the Cat's Anterior Auditory Field

B. Tian and J. P. Rauschecker

\section{RAPID PUBLICATIONS}

Saccadic Burst Neurons in the Fastigial Nucleus Are Not Involved in Compensating for Orbital Nonlinearities

K. Ohtsuka, H. Sato, and H. Noda

Stance Control in the Chronic Spinal Cat

C. A. Pratt, J. Fung, and J. M. Macpherson

Differences in Voltage-Dependent Sodium Currents Exhibited by Superficial

1981

and Deep Layer Neurons of Guinea Pig Entorhinal Cortex

S. Fan, M. Stewart, and R. K. S. Wong 
Trans-ACPD, a Metabotropic Receptor Agonist, Produces Calcium Mobilization and an Inward Current in Cultured Cerebellar Purkinje Neurons

D. J. Linden, M. Smeyne, and J. A. Connor

NO. 6. JUNE 1994

The Roles of GABAergic and Glycinergic Inhibition on Binaural Processing in the Dorsal Nucleus of the Lateral Lemniscus of the Mustache Bat

L. Yang and G. D. Pollak

GABA and Glycine Have Different Effects on Monaural Response Properties in the Dorsal Nucleus of the Lateral Lemniscus of the Mustache Bat

L. Yang and G. D. Pollak

The Activity of Interneurons During Locomotion in the In Vitro Necturus

Spinal Cord

M. Wheatley, K. Jovanović, R. B. Stein, and V. Lawson

2025

Reconstruction of Hippocampal CA1 Pyramidal Cell Electrophysiology by

Computer Simulation

E. N. Warman, D. M. Durand, and G. L. F. Yuen

2033

Characterization of Mechanosensitive Pelvic Nerve Afferent Fibers Innervating

the Colon of the Rat

J. N. Sengupta and G. F. Gebhart

Neuropharmacological Mechanisms Underlying Rhythmical Discharge in

Trigeminal Interneurons During Fictive Mastication

$T$. Inoue, S. H. Chandler, and L. J. Goldberg

Mechanical Entrainment of Fictive Locomotion in the Decerebrate Cat

D. J. Kriellaars, R. M. Brownstone, B. R. Noga, and L. M. Jordan

Properties of Sympathetic Reflexes Elicited by Natural Vestibular Stimulation:

Implications for Cardiovascular Control

B. J. Yates and A. D. Miller

2087

Characterization of the Membrane Ion Currents of a Model Molluscan Muscle, the Accessory Radula Closer Muscle of Aplysia californica. I. HyperpolarizationActivated Currents

V. Brezina, C. G. Evans, and K. R. Weiss

2046

2061

2074

Characterization of the Membrane Ion Currents of a Model Molluscan Muscle, the Accessory Radula Closer Muscle of Aplysia californica. II. Depolarization-Activated K Currents

V. Březina, C. G. Evans, and K. R. Weiss

Characterization of the Membrane Ion Currents of a Model Molluscan Muscle, the Accessory Radula Closer Muscle of Aplysia californica. III. Depolarization-

Activated Ca Current

V. Březina, C. G. Evans, and K. R. Weiss

Classification of Taste Responses in Brain Stem: Membership in Fuzzy Sets

R. P. Erickson, P. M. Di Lorenzo, and M. A. Woodbury

2093

Voltage-Dependent Modulation of $\mathrm{GABA}_{\mathrm{A}}$ Receptor Channel Desensitization in Rat Hippocampal Neurons

$K$ - W. Yoon

5-HT $\mathrm{HA}_{1 \mathrm{~A}}$ Receptor Linked to Inward-Rectifying Potassium Current In Hippocampal

CA3 Pyramidal Cells

D. Y. Okuhara and S. G. Beck

The Spatiotemporal Transfer Function of Crayfish Lamina Monopolar Neurons

R. M. Glantz and A. Bartels

Effects of Inhibition and Dendritic Saturation in Simulated Neocortical

Pyramidal Cells

P. C. Bush and T. J. Sejnowski

Effects of Ear Plugging on Single-Unit Azimuth Sensitivity in Cat Primary Auditory

Cortex. II. Azimuth Tuning Dependent Upon Binaural Stimulation

F. K. Samson, P. Barone, J. C. Clarey, and T. J. Imig 
Membrane Properties and Synaptic Responses of Interneurons Located Near the Stratum Lacunosum-Moleculare/Radiatum Border of Area CA1 in Whole-Cell

Recordings From Rat Hippocampal Slices

S. Williams, D. D. Samulack, C. Beaulieu, and J.-C. LaCaille

Regulation of $\mathrm{pH}$ in Rat Brain Synaptosomes. I. Role of Sodium, Bicarbonate, and Potassium

S. Sánchez-Armass, R. Martínez-Zaguilán, G. M. Martínez, and R. J. Gillies

Regulation of $\mathrm{pH}$ in Rat Brain Synaptosomes. II. Role of $\mathrm{Cl}^{-}$

R. Martínez-Zaguilán, R. J. Gillies, and S. Sánchez-Armass

2236

Pharmacological Similarity Between the Retinal APB Receptor and the Family

of Metabotropic Glutamate Receptors

N. Tian and M. M. Slaughter

Comparison of Neuronal Selectivity for Stimulus Speed, Length, and Contrast in the Prestriate Visual Cortical Areas V4 and MT of the Macaque Monkey

$K$. Cheng, T. Hasegawa, K. S. Saleem, and K. Tanaka

Reduction in Postsynaptic Inhibition During Maintained Electrical Stimulation of Different Nerves in the Cat Hindlimb

C. J. Heckman, J. F. Miller, M. Munson, K. D. Paul, and W. Z. Rymer

Modification in Activity of Medullary Respiratory-Related Neurons for Vocalization and Swallowing

C. R. Larson, Y. Yajima, and P. Ko

2294

Neural Activity in Cortical Area MST of Alert Monkey During Ocular

Following Responses

K. Kawano, M. Shidara, Y. Watanabe, and S. Yamane

2305

Neural Ensemble Coding in Inferior Temporal Cortex

P. M. Gochin, M. Colombo, G. A. Dorfman, G. L. Gerstein, and C. G. Gross

A- and C-Type Rat Nodose Sensory Neurons: Model Interpretations of Dynamic

Discharge Characteristics

J. H. Schild, J. W. Clark, M. Hay, D. Mendelowitz, M. C. Andresen,

and D. L. Kunze

2338

Whole-Cell and Single-Channel Calcium Currents in Guinea Pig Basal

Forebrain Neurons

W. H. Griffith, L. Taylor, and M. J. Davis

Functional Properties of Single Neurons in the Primate Face Primary Somatosensory

Cortex. I. Relations With Trained Orofacial Motor Behaviors

L.-D. Lin, G. M. Murray, and B. J. Sessle

Functional Properties of Single Neurons in the Primate Face Primary Somatosensory

Cortex. II. Relations With Different Directions of Trained Tongue Protrusion

L.-D. Lin, G. M. Murray, and B. J. Sessle

Functional Properties of Single Neurons in the Primate Face Primary Somatosensory

Cortex. III. Modulation of Responses to Peripheral Stimuli During Trained Orofacial

Motor Behaviors

L.-D. Lin and B. J. Sessle

Discrimination of the Direction of Motion on the Human Hand: A Psychophysical

Study of Stimulation Parameters

E. P. Gardner and B. F. Sklar

Parabrachial Area and Nucleus Raphe Magnus-Induced Modulation of Nociceptive and Nonnociceptive Trigeminal Subnucleus Caudalis Neurons Activated by

Cutaneous or Deep Inputs

C. Y. Chiang, J.W. Hu, and B. J. Sessle

Two Separate Inhibitory Mechanisms Shape the Responses of Dorsal Cochlear Nucleus Type IV Units to Narrowband and Wideband Stimuli

I. Nelken and E. D. Young

Multifocal Spontaneous Epileptic Activity Induced by Restricted Bicuculline

Ejection in the Piriform Cortex of the Isolated Guinea Pig Brain

M. De Curtis, G. Biella, M. Forti, and F. Panzica 
A Rhythmic Modulatory Gating System in the Stomatogastric Nervous System of Homarus gammarus. I. Pyloric-Related Neurons in the Commissural Ganglia F. Nagy, P. Cardi, and I. Cournil

A Rhythmic Modulatory Gating System in the Stomatogastric Nervous System of Homarus gammarus. II. Modulatory Control of the Pyloric CPG

F. Nagy and P. Cardi

A Rhythmic Modulatory Gating System in the Stomatogastric Nervous System of Homarus gammarus. III. Rhythmic Control of the Pyloric CPG

P. Cardi and F. Nagy

Receptive Fields and Functional Architecture of Macaque V2

J. B. Levitt, D. C. Kiper, and J. A. Movshon

2517

\section{RAPID PUBLICATIONS}

Long-Term Potentiation of Horizontal Connections Provides a Mechanism to Reorganize Cortical Motor Maps

G. Hess and J. P. Donoghue

Interstitial Volume Changes During Spreading Depression (SD) and SD-Like

Hypoxic Depolarization in Hippocampal Tissue Slices

J. Jing, P. G. Aitken, and G. G. Somjen

Quantal Mechanism of Long-Term Potentiation in Hippocampal

Mossy-Fiber Synapses

Z. Xiang, A. C. Greenwood, E. W. Kairiss, and T. H. Brown

2552

Evidence for Glutamate as the Olfactory Receptor Cell Neurotransmitter

D. A. Berkowicz, P. Q. Trombley, and G. M. Shepherd

Different Voltage Dependence of Transient and Persistent $\mathrm{Na}^{+}$Currents is

Compatible with Modal-Gating Hypothesis for Sodium Channels

A. M. Brown, P. C. Schwindt, and W. E. Crill

Kinetics of AP5 Dissociation From NMDA Receptors: Evidence for Two Identical

Cooperative Binding Sites

J. D. Clements and G. L. Westbrook

Potassium Channels Activated by GABA $_{B}$ Agonists and Serotonin in Cultured Hippocampal Neurons

L. S. Premkumar and P. W. Gage

Clonazepam Suppresses $\mathrm{GABA}_{\mathrm{B}}$-Mediated Inhibition in Thalamic Relay Neurons

Through Effects in Nucleus Reticularis

J. R. Huguenard and D. A. Prince

Lesions of the Posterior Commissure Disable the Vertical Neural Integrator of the Primate Oculomotor System

A. M. Partsalis, S. M. Highstein, and A. K. Moschovakis 


\section{Guest Referee Editors}

The Publications Committee of the American Physiological Society gratefully acknowledges the services of the following guest referee editors who assisted the Editorial Board in the review of manuscripts.
A. Agmon
G. E. Alexander
C. Alzheimer
V. E. Amassian
$P$. Andersen
R. A. Andersen
M. E. Anderson
M. Andreason
D. Angelaki
V. Apkarian
E. Arbas
J. Atick
G. Augustine
E. Banet
J. Barker
N. H. Barmack
C. J. Barnstable
B. Barres
D. S. Barth
P. Bawa
B. P. Bean
Y. Ben-Ari
G. Bennett
A. J. Berger
K. J. Berkley
A. Berthoz
J. M. Besson
M. D. Binder
A. B. Bonds
A. Borst
C. Bourque
E. N. Bruce
J. T. Buchanan
H. Burton
G. Buzsaki
C. Capaday
T. Carew
D. Carlen
P. L. Carlen
J. S. Carp
D. F. Cechetto
J. Chapin
C. E. Chapman
H. Chiel
A. Cinelli
B. Clark
J. Clements
H. T. Cline
R. Coggershall
L. B. Cohen
M. I. Cohen
C. Colby
H. Collewijn
W. F. Colmers
D. Colquhoun
P. J. Conn
J. Connor
B. Connors
A. Constantl
E. J. Cooper
M. Cooper
D. Coulter
M. D. Crutcher
S. G. Cull-Candy

\begin{tabular}{|c|c|}
\hline W. Darling & S. Hendry \\
\hline J. DeSimone & B. Hess \\
\hline K. Delaney & S. Hestrin \\
\hline C. Derby & T. P. Hicks \\
\hline D. Dickman & D. L. Hill \\
\hline R. Dingledine & D. S. Hoffman \\
\hline V. Dionne & N. Hogan \\
\hline J. Dostrovsky & J. M. Hollerbach \\
\hline R. Dubner & V. Honrubia \\
\hline R. P. Dum & D. C. Hood \\
\hline G. H. Duncan & F. B. Horak \\
\hline T. Dunwiddie & J. Hore \\
\hline R. G. Durkovic & I. Howard \\
\hline R. W. Dykes & J. E. Huettner \\
\hline T. Egan & J. Huguenard \\
\hline B. Ehrlich & H. Hultborn \\
\hline L. C. Evinger & A. L. Humphrey \\
\hline J. F. Baker & G. Jacobs \\
\hline D. S. Faber & M. F. Jacquin \\
\hline G. L. Fain & R. Jensen \\
\hline E. E. Fetz & J. Jock \\
\hline M. Filion & D. Johnson \\
\hline S. Firestein & J. W. Johnson \\
\hline M. Flanders & L. M. Jordan \\
\hline T. Flash & J. H. Kaas \\
\hline R. D. Foreman & J. F. Kalaska \\
\hline H. Forssberg & C. R. Kaneko \\
\hline G. Fortes & E. Kaplan \\
\hline S. Fox & B. S. Kapp \\
\hline M. E. Frank & G. M. Karst \\
\hline J. Freeman & J. S. Kauer \\
\hline R. D. Freeman & Y. Kawaguchi \\
\hline M. J. Friedlander & A. Kay \\
\hline J. H. Fuller & R. E. Kearney \\
\hline M. Gabriel & E. L. Keller \\
\hline B. Gahwiler & D. R. Kenshalo, Jr. \\
\hline H. Galiana & E. Keshner \\
\hline D. Gardner & W. M. King \\
\hline E. P. Gardner & W. Kingery \\
\hline G. F. Gebhart & S. T. Kitai \\
\hline W. S. Geisler & S. J. Kleene \\
\hline A. P. Georgopoulos & K.-D. Kniffki \\
\hline G. J. Giesler & J. Koester \\
\hline R. Gillette & N. Kopell \\
\hline W. F. Gilly & K. Krnjevic \\
\hline R. M. Glantz & D. M. Kullman \\
\hline J. W. Gnadt & T. Kumar \\
\hline J. M. Goldberg & I. Kupfermann \\
\hline G. L. Gottlieb & Y. Y. LaMarre \\
\hline C. K. Govind & J. R. Lackner \\
\hline W. H. Griffith & F. Lacquaniti \\
\hline S. Grillner & N. Lambert \\
\hline D. Guitton & J. L. Larimer \\
\hline P. B. Guthrie & C. R. Larson \\
\hline P. G. Guyenet & G. J. Laurent \\
\hline J. J. Hablitz & E. M. Leise \\
\hline T. Hales & M. S. Levine \\
\hline R. Hammer & P. Lipton \\
\hline H. O. Handwerker & S. Lipton \\
\hline R. Harris-Warrick & S. G. Lisberger \\
\hline N. Harrison & G. E. Loeb \\
\hline L. Hayward & E. Lothman \\
\hline C. Heckman & E. Luschei \\
\hline U. Heinemann & J. C. Lynch \\
\hline
\end{tabular}

A. B. MacDermott

P. R. MacLeish

R. L. MacDonald

K. L. Magleby

R. Malenka

N. Mano

R. H. Masland

J. Massion

D. N. Mastronarde

P. J. May

D. A. McAfee

R. W. McCarley

A. McClellan

E. W. McCleskey

D. R. McCrimmon

R. McDonald

O. B. McManus

B. Meech

R. W. Meech

L. M. Mendell

L. E. Miller

S. Mitchell

I. Mody

K. Mori

S. F. Morrison

T. J. Morrow

B. C. Motter

J. A. Movshon

D. P. Munoz

J. B. Munson

E. Nasi

S. A. Nawy

R. F. Nelson

T. R. Nichols

C. Nicholson

R. E. Norgren

R. A. North

M. C. Nowycky

M. Nussbaum

M. J. O'Donovan

S. Oleskevich

L. M. Optican

L. A. Palmer

L. Partridge

P. Pennefather

B. W. Peterson

J. Phillis

N. Picard

M. Pinter

M. Plummer

C. Polosa

T. P. Pons

R. K. Powers

C. A. Pratt

D. D. Price

W. A. Pulsinelli

R. Putnam

J. B. Ranck

A. Randall

M. Randic

C. H. Rankin

T. Raphan

P. E. Rapp

G. Rebec 


A. Rechtschaffen
S. Redman
R. C. Reid
A. Ribera
J. M. Rinzel
M. A. Rogawski
E. T. Rolls
S. Rosen
W. N. Ross
S. Rossignol
S. Rothman
P. Rowat
P. C. Ruben
P. Rudomin
W. Z. Rymer
J. N. Sanes
W. A. Sather
A. B. Saul
R. Sayer
H. Scharfman
S. S. Schiffman
W. Schlue
B. Schmitz
K. Scholz

A. B. Schwartz

P. Schwartzkroin

P. Schwindt

J. W. Scott

T. R. Scott

M. Segal

M. A. Segraves

D. Senseman

B. J. Sessle

M. Shelhamer

F. Sigworth

D. J. Simons

T. Sinkjaer

N. T. Slater

T. Slater

A. M. Smith

J. C. Smith

J. L. Smith

B. Spain

D. L. Sparks

P. D. Spear

A. Spencer

D. C. Spray

R. B. Stein
M. Steriade
G. Stoner
G. Strichard
D. G. Stuart
A. Surprenant
N. M. Szeverenyi
J. Tepper
W. T. Thach, Jr.
J. Theiler
S. Thompson
A. Thomson
D. L. Tomko
B. Trimmer
P. Q. Trombley
L. O. Trussell
B. Tuller
J. Van Der Steen
J. Van Gisbergen
P. Van Kan
T. A. Verdoorn
S. Vicini
J. D. Victor
C. J. Vierck
T. Vilis

J. Vitek

W. Wadman

J. T. Wall

P. D. Wall

E. T. Walters

C. Webber

K. Weiss

K.-G. Westberg

G. L. Westbrook

H. Wheal

J. White

B. L. Whitsel

A. W. Wiegner

J. T. Williams

A. Williamson

C. J. Wilson

F. Wilson

W. Wilson

R. H. Wurtz

K. W. Yau

A. J. Yool

F. E. Zajac

P. Zarzecki 


\title{
Interaction of Excitation and Inhibition in Processing of Pure Tone and Amplitude-Modulated Stimuli in the Medial Superior Olive
} of the Mustached Bat

\author{
BENEDIKT GROTHE \\ Zoologisches Institut der Universität München, 80333, Munich, Germany
}

\section{SUMMARY AND CONCLUSIONS}

1. In mammals with good low-frequency hearing, the medial superior olive (MSO) processes interaural time or phase differences that are important cues for sound localization. Its cells receive excitatory projections from both cochlear nuclei and are thought to function as coincidence detectors. The response patterns of MSO neurons in most mammals are predominantly sustained. In contrast, the MSO in the mustached bat is a monaural nucleus containing neurons with phasic discharge patterns. These neurons receive projections from the contralateral anteroventral cochlear nucleus ( $\mathrm{AVCN}$ ) and the ipsilateral medial nucleus of the trapezoid body (MNTB).

2. To further investigate the role of the MSO in the bat, the responses of 252 single units in the MSO to pure tones and sinusoidal amplitude-modulated (SAM) stimuli were recorded. The results confirmed that the MSO in the mustached bat is tonotopically organized, with low frequencies in the dorsal part and high frequencies in the ventral part. The $61 \mathrm{-kHz}$ region is overrepresented. Most neurons tested $(88 \%)$ were monaural and discharged only in response to contralateral stimuli. Their response could not be influenced by stimulation of the ipsilateral ear.

3. Only $11 \%$ of all MSO neurons were spontaneously active. In these neurons the spontaneous discharge rate was suppressed during the stimulus presentation.

4 . The majority of cells $(85 \%)$ responded with a phasic discharge pattern. About one-half $(51 \%)$ responded with a level-independent phasic oN response. Other phasic response patterns included phasic OFF or phasic ON-OFF, depending on the stimulus frequency. Neurons with ON-OFF discharge patterns were most common in the $61-\mathrm{kHz}$ region and absent in the high-frequency region.

5. Double tone experiments showed that at short intertone intervals the oN response to the second stimulus or the oFF response to the first stimulus was inhibited.

6. In neuropharmacological experiments, glycine applied to MSO neurons $(n=71)$ inhibited any tone-evoked response. In the presence of the glycine antagonist strychnine the response patterns changed from phasic to sustained $(n=35)$ and the neurons responded to both tones presented in double tone experiments independent of the intertone interval $(n=5)$. The effects of strychnine were reversible.

7. Twenty of 21 neurons tested with sinusoidally amplitudemodulated (SAM) signals exhibited low-pass or band-pass filter characteristics. Tests with SAM signals also revealed a weak temporal summation of inhibition in 13 of the 21 cells tested.

9. Application of strychnine shifted the upper SAM filter limits to higher modulation frequencies in all six neurons tested. The lower cutoff frequency of the response remained unchanged.

10. It is concluded that the timing of the monaural interaction of the direct excitatory, primary-like AVCN input and the indirect glycinergic inhibitory input via the MNTB shapes the responses of
MSO neurons to create either phasic on or phasic ofF discharge patterns. This time-dependent interaction may play a role in the processing of amplitude modulations caused by wing beats of flying insects.

\section{INTRODUCTION}

The superior olivary complex (SOC) of mammals consists of three principal nuclei: the lateral superior olivary nucleus (LSO), the medial superior olivary nucleus (MSO), and the medial nucleus of the trapezoid body (MNTB). The LSO and MSO are the first stations in the ascending auditory pathway that receive significant afferents from both ears. There is strong evidence that the LSO processes interaural intensity disparities whereas the MSO functions as a coincidence detector for interaural time disparities (ITDs) or interaural phase disparities (IPDs). The LSO receives excitatory afferents from the ipsilateral cochlear nucleus $(\mathrm{CN})$ and inhibitory projections from the contralateral $\mathrm{CN}$ via the MNTB. The MSO receives excitatory projections directly from both CNs (Brownell et al. 1979; Cant 1991; Goldberg and Brown 1968, 1969; Masterton and Diamond 1967; Masterton and Imig 1984; Yin and Chan 1990).

Because only animals with wide-set ears and good lowfrequency hearing are able to use IPDs and ITDs for sound localization, bats with closely spaced ears and high-frequency hearing should not possess a well-developed MSO (Harrison and Irving 1966; Irving and Harrison 1967; Masterton and Diamond 1967).

However, the mustached bat (Pteronotus parnellii) does not fit into this general scheme. Recent studies revealed the presence of a well-developed nucleus in the medial part of the superior olive. This nucleus is comparable with the MSOs of other mammals with respect to its location and cytoarchitecture (Zook and Casseday 1982a,b, 1985; Zook and Leake 1989), but it differs in the strength of connections. The ipsilateral projection to the MSO in the mustached bat is reduced. As a consequence of this, it is functionally quite different from the MSOs of nonecholocating mammals. MSO neurons in the mustached bat are predominantly monaural, responding only to contralateral sounds (Covey et al. 1991; Grothe 1990; Grothe et al. 1992).

Horseradish peroxidase (HRP) tracing studies in both nonecholocating mammals and bats have revealed two strong contralateral projections to the $\mathrm{MSO}$, one directly from the $\mathrm{CN}$ and one indirectly via the ipsilateral MNTB, 


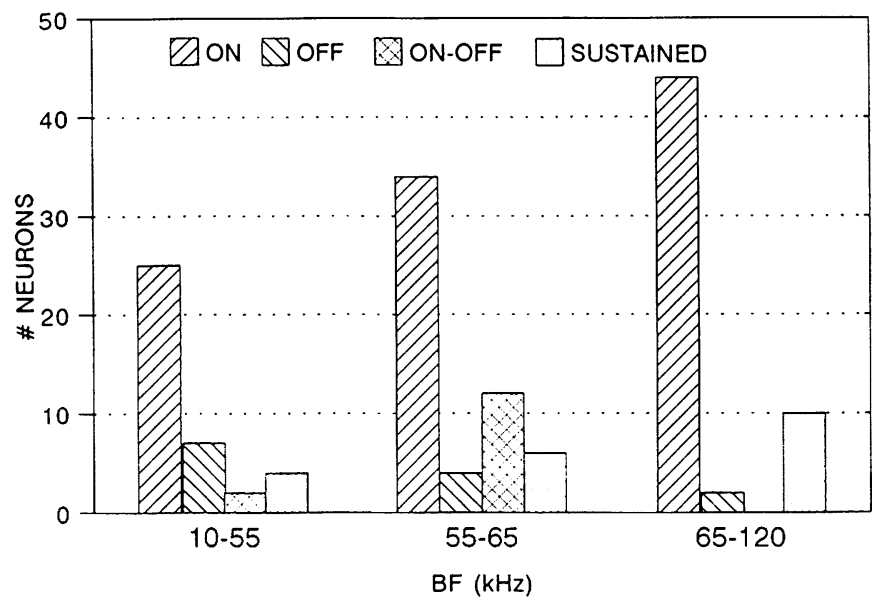

FIG. 1. Distribution of different discharge patterns for neurons with best frequencies (BFs) below the dominant harmonic of the constant frequency (CF) part of the echolocation call at $\left(\mathrm{CF}_{2}, \sim 61 \mathrm{kHz}\right)(10-55$ $\mathrm{kHz})$, around $\mathrm{CF}_{2}(55-65 \mathrm{kHz})$, and above $\mathrm{CF}_{2}(65-120 \mathrm{kHz})$. ON responses dominate in all frequency ranges. Note the lack of ON-OFF neurons with BFs $>65 \mathrm{kHz}$. Most ON-OFF responses (80\%) are found in the 55- to $65-\mathrm{kHz}$ range. ON includes neurons with a phasic oN response and a very weak sustained discharge (as the neuron in Fig. $2 C$ ). $n=150$ neurons.

which receives excitatory afferents from the contralateral CN (e.g., Cant and Casseday 1986; Warr 1982). In comparison with other species the direct projection delivered from the ipsilateral $\mathrm{CN}$ in the mustached bat is extraordinarily weak (Covey et al. 1991; Grothe 1990; Grothe et al. 1992).

The MNTB contains glycine immunoreactive cells (Wenthold and Hunter 1990; Wenthold et al. 1987) and its projections are known to be responsible for the well-described contralateral inhibition in LSO neurons (e.g., Moore and Caspary 1983; Sanes 1990; Zook and DiCaprio 1988). Since the MNTB sends a large projection to the ipsilateral MSO in the mustached bat, there should be a strong inhibitory effect on MSO neurons, resulting in a monaural interaction of excitation and inhibition. This interaction of excitatory and inhibitory inputs, both from the contralateral ear, should influence the general response patterns of MSO neurons.

Searching for flying insects in cluttered surroundings, the mustached bat emits echolocation calls with a duration of $\sim 30 \mathrm{~ms}$. These biosonar signals consist of a long constantfrequency $(\mathrm{CF})$ component preceded and terminated by short FM parts (Schnitzler 1970). The mustached bat's entire auditory system is adapted to processing frequencies corresponding to the three harmonics of the CF part of the echolocation call, especially the dominant harmonic at $\sim 61 \mathrm{kHz}\left(\mathrm{CF}_{2}\right)$ (Kössl and Vater 1985; Suga 1989; Suga et al. 1975). Behavioral tests of CF-FM bats (von der Emde 1990; Goldman and Henson 1977) as well as recordings of echoes from different insects (Henson et al. 1987; Kober and Schnitzler 1990) and cochlear microphonics (Henson et al. 1987) indicate that periodic amplitude and frequency modulations within the echo play an important role in prey detection and recognition of different insects.

In this study I investigated neurophysiologically and neuropharmacologically the effect of the glycinergic MNTB projection on the response patterns of MSO neurons. It is the purpose of this study to illuminate the func- tion of the MSO in the mustached bat and give some hints about the function of the inhibitory projections to the MSO, which seem to be a general mammalian phenomenon (Cant 1991; Cant and Hyson 1992; Goldberg and Brown 1969; Grothe and Sanes 1992, 1993; Kuwabara and Zook 1992; Smith and Banks 1992; Yin and Chan 1990).

Parts of this study have been published previously in a brief version (Grothe et al. 1992).

\section{METHODS}

Eleven Jamaican bats of the species Pteronotus p. parnellii were used in this study. During surgery the bats were anesthetized with ketamine/xylazine ( $10 \mathrm{mg}$ ketamine $/ \mathrm{ml}+2 \%$ xylazine; $1 \mathrm{ml} / 100$ $\mathrm{g}$ body wt) injected subcutaneously. A metal bolt serving to fix the head in the stereotaxic apparatus was mounted on the bat's skull and a small hole was drilled above the cerebellum. The animals were placed in a holder in an experimental chamber heated to $\sim 32^{\circ} \mathrm{C}$. The surgical wound was treated with local anesthetic (xylocaine) and water was occasionally given to the bats. Recording sessions started after recovery from anesthesia. The electrode was positioned stereotaxically and penetrated the intact cerebellum to reach the MSO in $>4,200 \mu \mathrm{m}$ recording depth.

For conventional extracellular single unit recording, fine-tipped glass electrodes filled with $3 \mathrm{M} \mathrm{KCl}$ (impedance of 4-20 M $\Omega$ ) were used. For neuropharmacological investigations, glass electrodes were glued to a five- barrel glass pipette ("piggy-back" electrodes; Moore and Caspary 1983). The collective tip diameter of the multibarrel was $5-15 \mu \mathrm{m}$, the tip of the recording electrode protruded $\sim 5-20 \mu \mathrm{m}$. Individual barrels contained $\gamma$ - aminobutyric acid (GABA) (0.5 M, pH 3.5-4.0), glycine (0.5 M, pH 4.0) and the specific antagonists bicuculline (methiodide, $0.005 \mathrm{M}, \mathrm{pH} 3.0$ ) and strychnine $(-\mathrm{HCl}, 0.01 \mathrm{M}, \mathrm{pH} \mathrm{3.5)}$. The fifth barrel was filled with $1 \mathrm{M}$ sodium acetate and served as the balance channel. Stimuli were presented in closed field conditions via specially designed earphones (Schlegel 1977). The isolation between the two ears was $>40 \mathrm{~dB}$ SPL.

Stimuli consisted of single pure tone pulses (rise-fall times 0.5 $\mathrm{ms}$, duration $30 \mathrm{~ms}$, repetition rate $0.5 \mathrm{~Hz}$ ), double tone pulses with variable temporal delay, and sinusoidally amplitude-modulated (SAM) tones. SAM signals were varied from 0 to $1 \mathrm{kHz}$ modulation frequency with $100 \%$ modulation depth.

For each neuron, the best frequency (BF) and the tuning curve were determined using audiovisual criteria. Binaural response properties were tested using pure tones with different interaural intensity and frequency disparities and ITDs. Temporal response patterns, rate-level functions and latencies to different sound pressure levels were determined from peristimulus time histograms (PSTHs) calculated from 60 presentations of each stimulus. The bin time for generating most of the PSTHs presented here was $0.5 \mathrm{~ms}$.

Response properties during or shortly after drug application were compared with those under control conditions recorded before iontophoresis or after full recovery from drug effects. Stimulus parameters and drug application parameters were not changed until full recovery from previous drug effects was achieved.

The sample of MSO cells tested with different parameters and full recovery is limited because of technical difficulties inherent in the experimental approach. During penetrations through the intact cerebellum the multibarrels tended to block or the tips of the recording electrodes were often separated from the multibarrel. Furthermore, recovery times of single units after strychnine applications could last $>15 \mathrm{~min}(\leq 30 \mathrm{~min})$.

At the end of each experiment, HRP was iontophoretically injected into the MSO to localize recording sites and to investigate the projection patterns. Methods for iontophoretic HRP injection, 

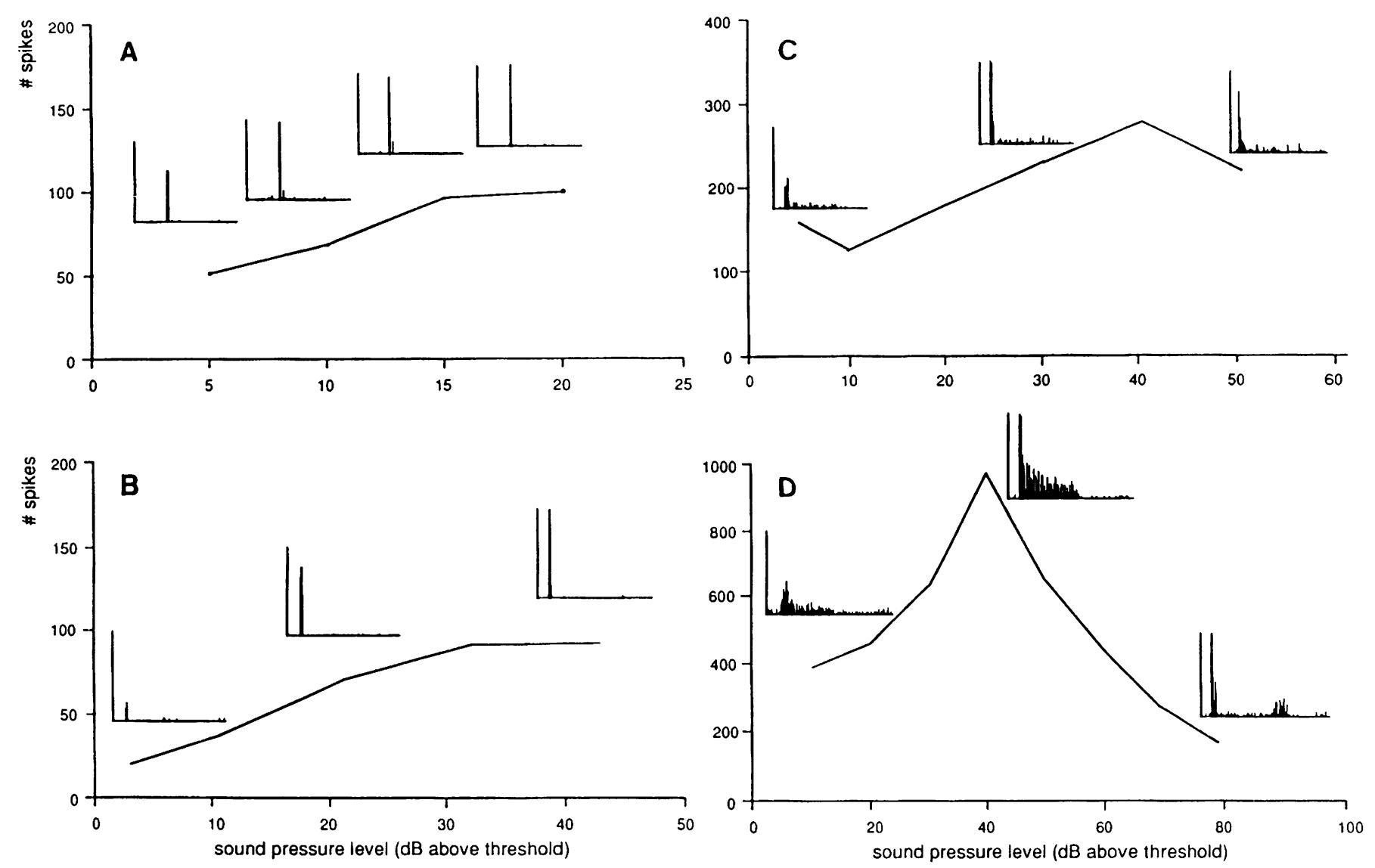

FIG. 2. Four different examples of rate-level functions with selected peristimulus time histograms (PSTHs). Each point represents the total number of spikes to 60 test tones at a given sound pressure level. Test tones were 30 -ms pure tones at the neuron's BF. Note that discharge patterns did not change with increasing stimulus level in cases $A-C$ (BFs: $54.8,26.0$, and $64.8 \mathrm{kHz}$ ). $D$ : atypical nonmonotonic rate-level function due to a level-dependent change of the response pattern from phasic-tonic to an ON-OFF. The neuron's BF was $61.2 \mathrm{kHz}$, close to the $\mathrm{CF}_{2}$. The binwidth for the PSTHs is $0.5 \mathrm{~ms}$.

perfusion, and histochemistry followed procedures described in Feng and Vater (1985).

\section{RESULTS}

The BFs of MSO neurons ranged from 10 to $120 \mathrm{kHz}$ ( $n=252$ ), with $37 \%$ of BFs located in the frequency range corresponding to the dominant second harmonic of the echolocation call between 55 and $65 \mathrm{kHz}$. Reconstructions of the electrode tracts show that low frequencies are represented dorsolaterally and high frequencies ventromedially ( see also Covey et al. 1991).

The responses of 249 neurons were tested under binaural stimulus conditions. The predominant response type was monaural. In $88 \%$ of the neurons tested, stimulation of the ipsilateral ear had no effect but excitation resulted from stimulation of the contralateral ear (OE). Only one cell responded exclusively to ipsilateral stimulation without being affected by contralateral stimulation (OE). A few neurons showed binaural response characteristics like ipsilateral stimulation alone having no effect but facilitating the response to contralateral tones (OF/E) $(2 \%)$, being inhibited by ipsilateral stimulation and excited by contralateral stimulation (IE) (4\%), being excited from both sides (EE) (4\%), and being excited by ipsilateral stimulation and inhibited by contralateral stimulation (IE) ( 1 cell). Without ex- ception these binaural neurons were located at the peripheral margins of the nucleus.

The majority of MSO neurons exhibited no spontaneous activity. Only $11 \%$ of the units $(n=249)$ showed low spontaneous activity ( $<1$ spike/s). In these neurons the spontaneous discharge rate was suppressed during the stimulus presentation.

The majority $(85 \%)$ of units had phasic response patterns: $51 \%$ of these were purely oN, $16 \%$ were oN with a weak sustained component, $9 \%$ were oFF, and $9 \%$ were ONOFF. Only $12 \%$ had sustained response patterns, even though these are the predominant response type in the cat and dog MSO (Caird and Klinke 1983; Goldberg and Brown 1969; Guinan et al. 1972). The distribution of the different response patterns depended on the BF of the units. Figure 1 shows the distribution of the different response patterns as a function of BF in three frequency ranges: $<55$ $\mathrm{kHz}$, between 55 and $65 \mathrm{kHz}$, and $>65 \mathrm{kHz}$. Most neurons (12/14) with ON-OFF responses had a $\mathrm{BF}$ around the $\mathrm{CF}_{2}$ component of the echolocation call. Neurons with ON-OFF responses were not observed in the higher frequency range.

The temporal response patterns of most MSO neurons did not change with sound level. Rate-level functions were mostly monotonic with dynamic ranges $<25 \mathrm{~dB}$ (Fig. 2, $A$ and $B)$. Only some ON-OFF neurons tuned to the $\mathrm{CF}_{2}(\sim 61$ $\mathrm{kHz}$ ) had prominent nonmonotonic rate-level functions 


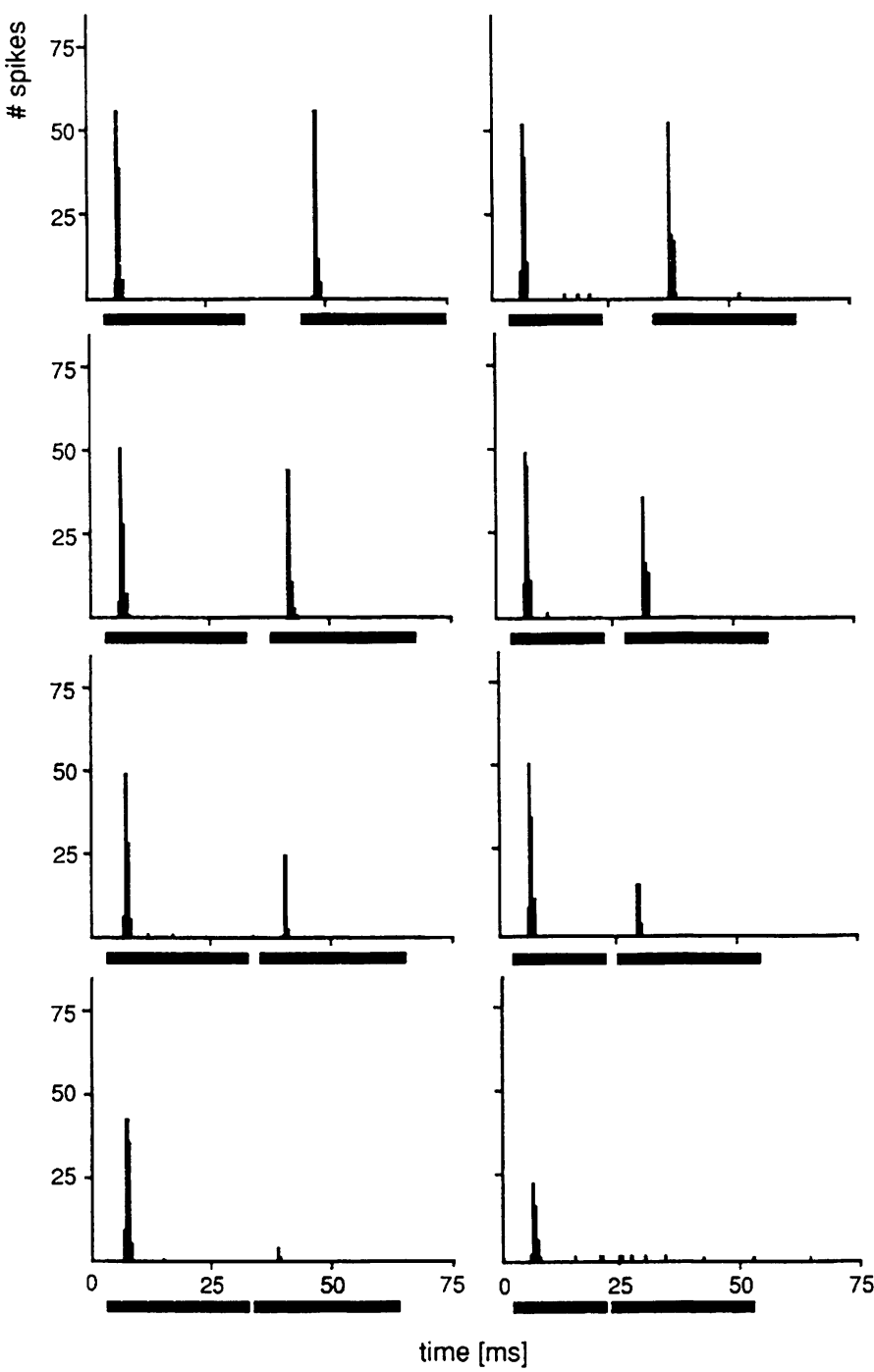

FIG. 3. PSTHs of a single unit during a two-tone experiment (ordinate is the total number of spikes to 60 stimulus repetitions: binwidth is 0.5 $\mathrm{ms})$. The stimulus levels of both tone bursts were set to $10 \mathrm{~dB}$ SPL above threshold, presented at the neuron's BF $(109.3 \mathrm{kHz})$. When the interval between tone bursts was long. the neuron responded to both tone bursts with an oN discharge. Shortening the interburst duration from $10 \mathrm{~ms}$ ( $/ \mathrm{st}$ row) to 5, 3, and I ms (4th row') caused the second response to decrease until it was finally completely blocked at $\leq 1 \mathrm{~ms}$. This effect was independent of the duration of the 1st tone (left column: $30 \mathrm{~ms}$; right column: 20 $\mathrm{ms}$ ). The effect was identical when a 10 -ms 1 st tone was used (not presented here).

due to the fact that their response patterns changed from sustained to ON-OFF when the sound pressure level increased (Fig. 2D).

Summarizing these data, MSO neurons can be characterized as OE neurons (excited only by contralateral sounds) without spontaneous activity and predominantly level-independent phasic response patterns.

\section{Monaural stimulation with tone pairs}

To determine whether the phasic response patterns were due to a monaural interaction of excitation and inhibition within the MSO, two-tone experiments were performed on 14 cells ( 11 neurons with oN responses, 3 with ofF responses). Two identical tone burst stimuli separated by a variable interval were presented. The interburst interval duration was initially $10 \mathrm{~ms}$ and was shortened progressively.

Figure 3 shows PSTHs of a neuron with a typical oN response pattern. If the two tone bursts were separated by an interburst interval of $10 \mathrm{~ms}$, prominent oN responses to both stimuli occurred ( 1 st row in both columns). Shortening of the interburst interval led to a progressive decrease of the second oN response. With an interburst duration of 1 $\mathrm{ms}$, the response to the second tone burst was inhibited. Comparing the left and the right columns of Fig. 3 it becomes clear that during the stimulus there was inhibition that surpassed the stimulus duration by $>1 \mathrm{~ms}$, independent of the duration of the first stimulus ( $30 \mathrm{~ms}$ at the right, $20 \mathrm{~ms}$ at the left $)$. All of the 11 on neurons tested exhibited this type of interaction between excitatory and inhibitory inputs.

Figure 4 shows the response of a neuron exhibiting an OFF response and a $\mathrm{BF}$ of $\sim 56 \mathrm{kHz}$. In this neuron the

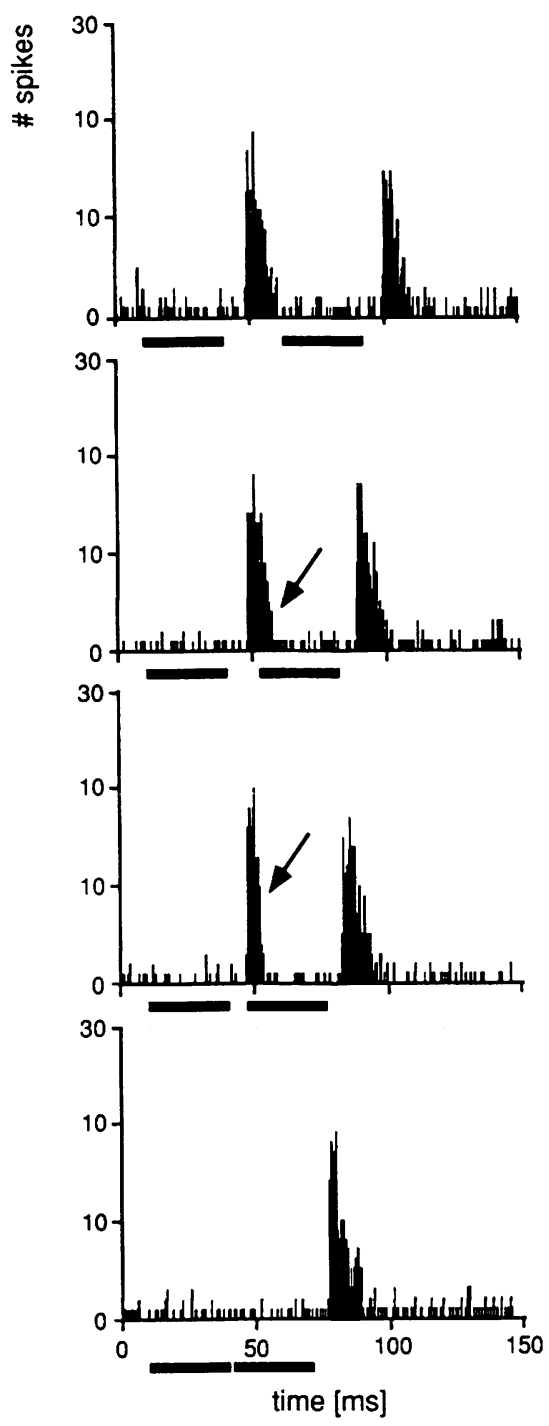

FIG. 4. Same test as shown in Fig. 8, but for a neuron with an ofF response $(\mathrm{BF}: 56.0 \mathrm{kHz})$. In this case the shortening of the interburst duration $(10,5.3$, and $1 \mathrm{~ms})$ caused a shortening of the 1 st response $(\rightarrow)$ and finally its disappearance. Ordinate: total number of spikes to 60 stimulus repetitions. Binwidth is $0.5 \mathrm{~ms}$. 


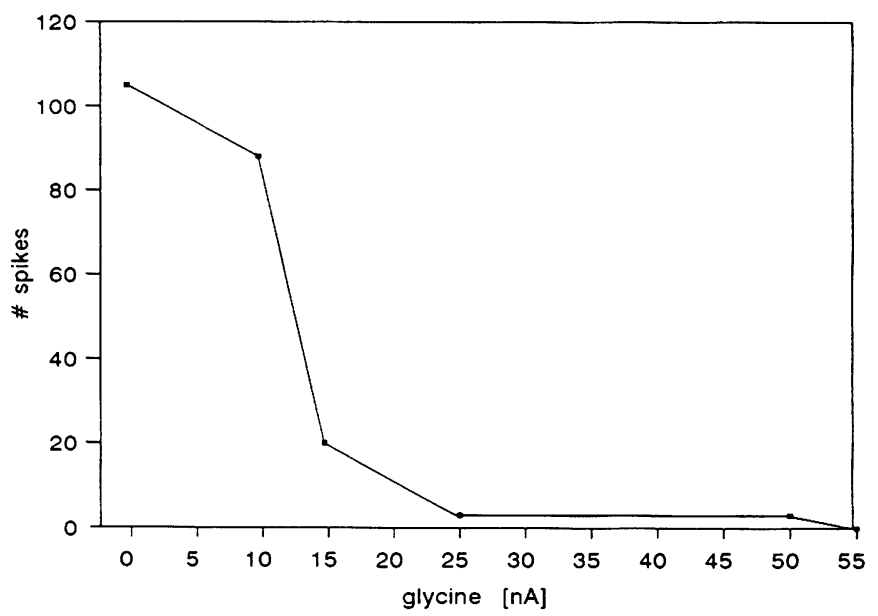

FIG. 5. Total number of evoked spikes to 60 stimulus repetitions during glycine delivery as a function of the current (nanoamperes) used to deliver glycine iontophoretically. The neuron's BF was $110 \mathrm{kHz}$. The steep decrease of the neuron's discharge between 10- and 15-nA current shows the activity of the inhibition by glycine. Holding current: $-15 \mathrm{nA}$.

reduction of the interburst interval caused the duration of the first response to shorten $(\rightarrow)$ until finally it disappeared. The responses of the other two ofF neurons tested with tone pairs were similar.

These experiments indicate that there is an interaction between inhibitory and excitatory influences and that the duration of the inhibition lasts at least as long as the duration of the stimulus. In the first case reported above, inhibition extended beyond excitation, and in the second case inhibition preceded the excitation or occurred simultaneously. This result indicates that differences in the timing of the monaural excitation and inhibition can create different response patterns.

\section{Neuropharmacological experiments}

To determine whether the predominantly phasic response patterns of MSO units in the mustached bat result from synaptic integration of different projections to the $\mathrm{MSO}$, the inhibitory neurotransmitters glycine and GABA as well as their antagonists bicuculline and strychnine were applicated iontophoretically.

Application of GABA or bicuculline caused a change in tone-evoked or spontaneous activity in only 6 of 58 neurons. All of these neurons were located within a marginal band of cells along the dorsomedial edge of the MSO. In no case did GABA or bicuculline affect the responses of units that were located within the main body of MSO.

Within the main body of the MSO, changes in the response patterns of single units could only be evoked by glycine or strychnine. Glycine inhibited sound-evoked responses in $83 \%$ of 71 neurons tested. The threshold for glycine effects ranged from 3 to $25 \mathrm{nA}$. In most cases the effects mediated by glycine were fast, within 1-3 s, and recovery was also rapid, within a few seconds. Thus inhibition could only be observed during glycine delivery. Figure 5 shows the dose-dependent effect of glycine over a current range of 10-55 nA. The total number of spikes evoked by 60 stimu- lus repetitions decreased from 105 to 3 spikes. The left column in Fig. 6 shows a neuron with an oN response pattern (top histogram) before delivery of glycine. In the presence of the inhibitory transmitter glycine (middle histogram) this ON response was completely inhibited, but a few seconds after the end of the glycine application, the oN response recovered (bottom histogram).

Strychnine was delivered iontophoretically to 35 units. Compared with glycine, the effects of strychnine were much slower, with the maximal effect typically occurring 3-5 min after the beginning of the strychnine delivery. Recovery also took longer, $\leq 30 \mathrm{~min}$. The slow action of strychnine is illustrated in Fig. 7. Only 3 min after terminating the iontophoretic application of strychnine (which lasted in this case for $4 \mathrm{~min}$ ) the total number of spikes evoked began to increase. The maximal effect occurred at $\sim 6 \mathrm{~min}$, and recovery was virtually complete after $10 \mathrm{~min}$. In most units, strychnine changed the threshold for inhibition by glycine. As indicated by asterisks in Fig. 7, the threshold for complete suppression of each response by glycine remained elevated for $>20 \mathrm{~min}$ after strychnine application. All tests, with the exception of the one shown in Fig. 7, were performed during continuous strychnine delivery and began 5 min after initiating strychnine iontophoresis.

Application of strychnine resulted in low-level spontaneous activity in otherwise nonspontaneously active cells. In those cells that were spontaneously active, strychnine increased the rate slightly $(\leq 30 \%)$. In all units strychnine increased the tone-evoked discharge levels (100-500\%). This increase resulted from a shift from phasic to sustained responses. Figure 6 presents two examples of these changes in response pattern (middle and right columns). The middle column shows a phasic on response, which changed to a sustained response pattern in the presence of strychnine. The OFF response in the right column (top histogram) changed to a sustained response during strychnine application. After several minutes the OFF response recovered (bottom histogram). That the main discharge during the ofF response occurred later than the end of the sustained response seen in the presence of strychnine indicates that the OFF response is a rebound effect due to neuronal inhibition.

None of the five neurons within the $61-\mathrm{kHz}$ area that showed a frequency-dependent ON-OFF response could be influenced by any drug tested. Because of the small sample it cannot be decided whether there is a lack of glycinergic (or GABAergic) projections, whether the experimental circumstances prevented a reaction to the drugs, or whether the response patterns reflect cochlear mechanical phenomena. However, the responses of one of these cells were recorded during a penetration with successful drug tests of an ON neuron with a BF of $60,5 \mathrm{kHz}$ positioned $50 \mu \mathrm{m}$ dorsally to it, suggesting a lack of GABAergic as well as glycinergic projections to the ON-OFF neuron.

The magnitude of response to the second tone in twotone experiments was influenced by application of strychnine $(n=5)$. Figure 8 demonstrates that the inhibition due to the first tone was reduced by strychnine.

In summary, there is evidence for a sustained excitatory input to MSO neurons from the contralateral CN. The phasic response activity of the MSO cells is created by an addi- 



FIG. 6. Three medial superior olivary nucleus (MSO) neurons and the changes in their response patterns induced by delivering the inhibitory transmitter glycine or the glycine antagonist strychnine. Ordinate: total number of spikes to 60 stimulus repetitions. Binwidth is $0.5 \mathrm{~ms}$. Black bars: tone burst duration. Left column: a neuron with a $\mathrm{BF}$ at $86 \mathrm{kHz}$, responding with a phasic oN response before ( $t$ op row), during (middle row), and after delivering glycine (bottom row: current: $25 \mathrm{nA}$ ). Glycine blocked the response to the 30-ms test tone immediately. Middle column: the normal on response (top row) of this neuron (BF: $53.3 \mathrm{kHz}$ ) was blocked by delivering glycine (middle row). When strychnine was applied a sustained response pattern resulted. This sustained response presumably represents the pattern of the excitatory input. Right column: this neuron (BF: $66.8 \mathrm{kHz}$ ) responded with a rebound OFF response (top row). In the presence of strychnine, which blocked the inhibitory input, the response pattern changed from off to sustained, revealing the presence of a sustained excitatory input. After several minutes the strychnine effect decreased and the rebound off response recovered (bottom row). Glycine blocked the spontaneous activity and the OFF response completely for this unit (not shown here).

tional sustained inhibitory input. The inhibitory input is glycinergic and probably arises from the ipsilateral MNTB. The latencies of the sustained excitation and sustained inhibition differ from neuron to neuron and determine whether discharges occur at the beginning or the end of a stimulus. The data suggest that latency differences varied from none (neurons with rebound OFF responses) to a 5-ms delay in the onset of inhibition (neurons with on responses).

\section{Two-tone masking experiments}

Seven neurons were tested by a monaural two-tone paradigm. A signal at the BF of the neuron $10 \mathrm{~dB}$ above threshold, $10 \mathrm{~ms}$ in duration and having a $10-\mathrm{ms}$ delay was added to a 30-ms masker at the same intensity. The frequency of the masker was varied systematically. Figure 9 shows the result of one such experiment. The top panel shows the total number of spikes attributed to the test signal and the masker as a function of masker frequency. The bottom of the figure depicts PSTHs at five different masker frequencies. The ON response to the BF signal is suppressed by masker frequencies within a broad frequency range (from 4 $\mathrm{kHz}$ below $\mathrm{BF}$ to $20 \mathrm{kHz}$ above $\mathrm{BF}$ ), even though there is no response to the masker. This could be explained by either a broader tuning of the individual inhibitory inputs or, more likely, by a convergence of different inhibitory inputs. The results from the six other neurons tested were similar.

\section{Amplitude modulations}

The results described above suggest that the response activity of MSO neurons is governed by the relative timing of excitatory and inhibitory inputs. Thus distinct response patterns would be expected when MSO neurons are tested with amplitude modulated (AM) signals ( see DISCUSSION). Therefore 21 MSO units were tested with SAM signals. Synchronization of discharge activity to the period of the SAM signals was observed in 20 neurons. These neurons differed in their ability to follow SAM signals. Figure 10 shows the PSTHs of a phasic ON neuron at different SAM frequencies (carrier frequency: $26 \mathrm{kHz}=\mathrm{BF}$ ). At modulation frequencies $<40 \mathrm{~Hz}$ the neuron did not respond to every cycle (on average only every other cycle) and its timing was less precise than for higher SAM frequencies. From $40-$ to $80-\mathrm{Hz}$ SAM frequencies the neuron's discharge was phase-locked to each modulation period. At a modulation frequency of $\geq 100 \mathrm{~Hz}$ there was only a phasic response to the first modulation cycle followed by a nonsynchronized sustained response that did not appear during presentation of nonmodulated stimuli. 


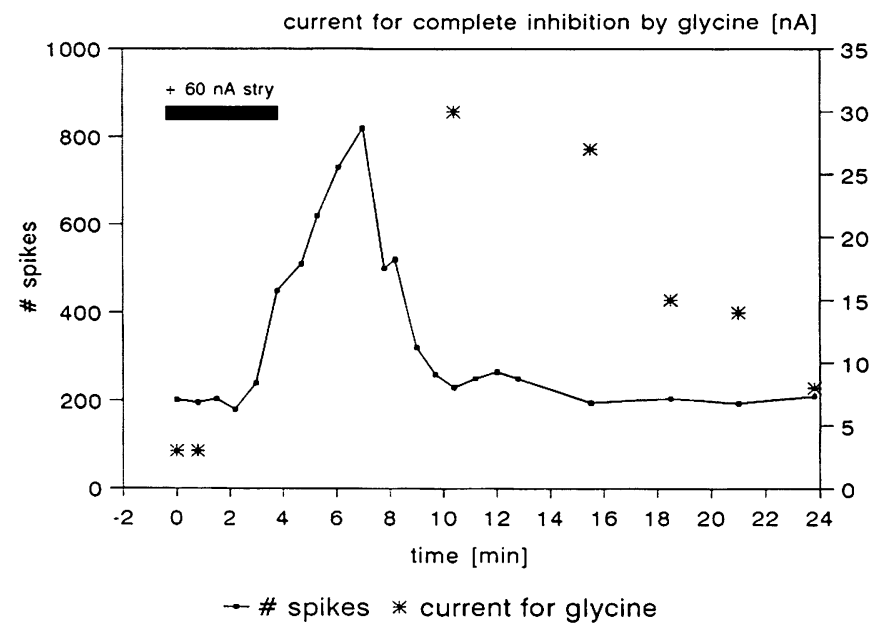

FIG. 7. The effect and time course of iontophoretically delivering the glycine antagonist strychnine are illustrated by plotting the total number of spikes evoked to 60 stimuli (left ordinate) as a function of time. The stimulus was a tone burst at the neuron's $B F(66.8 \mathrm{kHz}), 10 \mathrm{~dB}$ above threshold. Dark bar: duration of the strychnine application. Asterisks: glycine current necessary to block the neuron's response completely (right ordinate). Clearly visible is the dramatic effect of strychnine (number of spikes up to $>300 \%$ of the original discharge) and its long-lasting antagonism of the glycinergic inhibition.

The response of the OFF neuron shown in Fig. 11 was clearly synchronized to AM cycles at low modulation frequencies ( $30-\mathrm{Hz}$ SAM frequency) and remained synchronized at modulation frequencies of $\leq 200 \mathrm{~Hz}$. For modulation frequencies of $\geq 300 \mathrm{~Hz}$ there was only one OFF response after the last AM cycle of the stimulus.

Figure 12 shows a plot of the number of spikes normalized to the maximal output for a single SAM cycle as a function of SAM frequency, as well as the vector strength of the SAM correlated response. On the basis of these criteria the OFF neuron in Fig. 11 showed low-pass filter characteristics (Fig. $12 \mathrm{~B}$,) whereas the phasic on neuron shown in Fig. 10 exhibited not only an upper cutoff frequency but some kind of band-pass filter characteristic with a weak response at SAM frequencies $<40 \mathrm{~Hz}$ (Fig. 12 $\mathrm{A}$; see below).

Using $100 \%$ modulation depth, $60 \%(12 / 20)$ of SAMsensitive units tested had low-pass filter characteristics with upper limits between 100 and $500 \mathrm{~Hz}$, mostly $\sim 250 \mathrm{~Hz}$; the remainder $40 \%(8 / 20)$ showed an additional decrease of discharge activity for low SAM frequencies ("band-pass" filter characteristics). There was no correlation between a unit's filter characteristic and parameters like BF, discharge pattern, or location within the MSO. The steepness of the high- frequency cutoffs of the SAM functions differed among cells. Fifty percent of cells had rather steep high-frequency cutoff functions, as shown in detail in Fig. 13. For this unit, a dramatic decrease in the response to the SAM stimulus occurred between $200-$ and $250-\mathrm{Hz}$ SAM frequencies. This is illustrated in $10-\mathrm{Hz}$ steps. This figure also exhibits an effect that was not obvious in the example reported above: at higher AM frequencies the last phaselocked discharges were removed first. Moreover, they did not disappear at once, but the probability of a spike occurring decreased within a certain range. Such "adaptation" from a sustained to phasic response could be observed in
$65 \%$ of the neurons. Because anteroventral cochlear nucleus (AVCN) neurons are known to synchronize discharges to higher AM frequencies (see DISCUSSION) the shift of MSO response from sustained to phasic at higher AM frequencies is probably due to a temporal summation of inhibition.

One neuron did not phase-lock to SAM stimuli but nevertheless exhibited discharge patterns that depended on the modulation frequency (Fig. 14). This neuron did not respond to SAM stimuli with modulation frequencies $<130$ $\mathrm{Hz}$, but it did respond with an ON-OFF discharge to SAM frequencies between 130 and $180 \mathrm{~Hz}$ and with an ON response to SAM frequencies $>200 \mathrm{~Hz}$.

\section{Influence of strychnine on SAM transfer functions:}

To test whether the filter characteristics of MSO units for SAM stimuli are due to synaptic integration of the timeshifted excitatory and inhibitory inputs, the upper cutoff of MSO cells was examined under the influence of strychnine, which eliminates the glycinergic inhibition from the

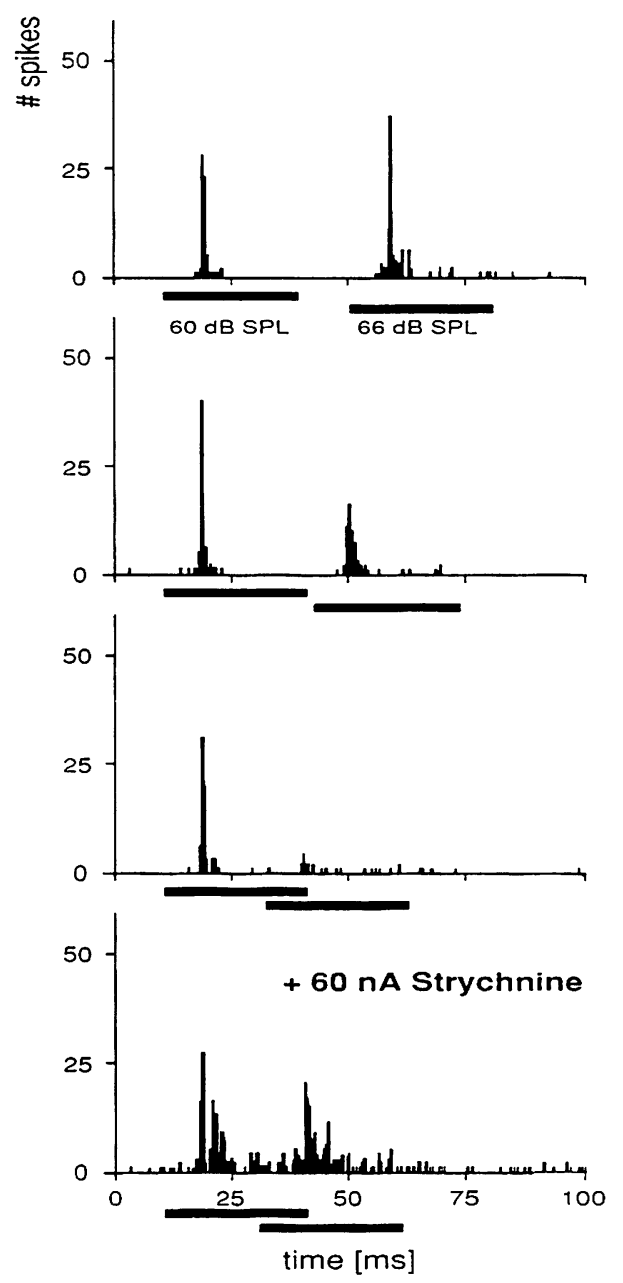

FIG. 8. Overlapping 2-tone experiment using a pair of 30-ms pure tones at the neuron's BF $(55.5 \mathrm{kHz})$. The 1 st tone was presented at $60 \mathrm{~dB}$ SPL, the 2 nd at $66 \mathrm{~dB}$ SPL. The shortening of the interburst interval ( 8 and $1 \mathrm{~ms}$ ) and finally the overlapping ( $4 \mathrm{~ms}$ ) of the 2 signals resulted in a suppression of the ON response to the 2 nd tone. In the presence of strychnine the 2 nd tone evoked a response. Ordinate is the total number of spikes to 60 stimulus repetitions. Binwidth is $1 \mathrm{~ms}$. 


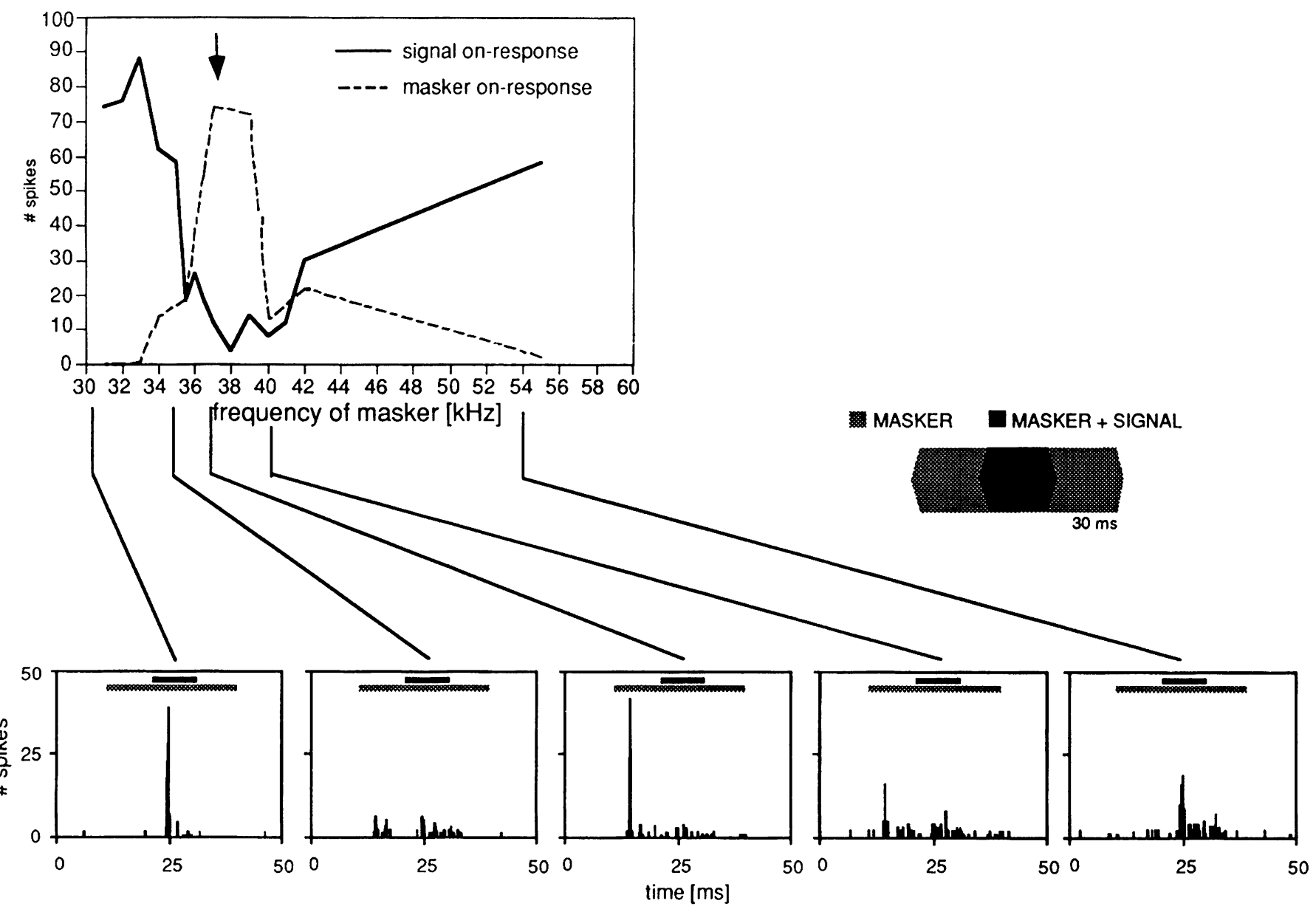

FIG. 9. Measurement of the frequency tuning of the inhibitory input as tested by a simultaneous masking experiment. The test signal (duration: $10 \mathrm{~ms} ; 36.6 \mathrm{kHz}=$ neuron's BF; $10 \mathrm{~dB}$ above threshold) was presented in the center of a $30-\mathrm{ms}$ masker (same SPL, variable frequency). The frequency of the masker was varied between 31 and $55 \mathrm{kHz}$. Graph: total number of spikes to 60 presentations attributed to the test signal (-) and the masker (- - ) as a function of the masker frequency. Selected PSTHs are shown below. The frequency range over that the response to the test tone was suppressed was broader than the frequency range evoking a discharge to the masker. Binwidth of the PSTHs is $1 \mathrm{~ms}$.

MNTB. Such tests were performed in five cells (4 oN neurons, 1 ofF neuron). In all neurons tested the upper SAM frequency limits shifted toward higher modulation rates when strychnine was applied.

Figures 15 and 16 show two examples of this shift. One neuron had an OFF response pattern and no synchronized response activity for SAM frequencies $>200 \mathrm{~Hz}$ (Fig. 15). For example, the vector strength for the $250-\mathrm{Hz}$ SAM frequency was 0.08 but improved in presence of strychnine to 0.64 . In this neuron strychnine shifted the SAM filter limit up to $600 \mathrm{~Hz}$. The second neuron had a phasic on response pattern with a weak tonic component and a clearly decreased synchronization at SAM frequencies $>200 \mathrm{~Hz}$ (Fig. 16). In this case strychnine shifted the SAM filter limit from $\sim 200 \mathrm{~Hz}$ up to $\sim 600 \mathrm{~Hz}$. The 0.5 point of the vector strength is at $180 \mathrm{~Hz}$ for the control function, but between 600 and $800 \mathrm{~Hz}$ in the presence of strychnine. These results suggest that glycinergic inhibition is one factor that determines the upper filter frequency of the modulation transfer function in MSO neurons.

In contrast, in both units responding to SAM signals with band-pass filter characteristics the response to low modulation frequencies was not influenced by strychnine.

\section{DISCUSSION}

\section{Monaural and binaural response characteristics}

The classical picture of the MSO in mammals is that of a binaural nucleus that receives excitatory input from both CNs and functions as a coincidence detector for ITDs or IPDs. In agreement with Covey et al. (1991), the data presented here describe the MSO in the mustached bat as a monaural nucleus with $>88 \%$ of the units exhibiting OE response characteristics. The few binaural neurons encountered in the present study were located at the dorsomedial border of the MSO, perhaps belonging to the dorsomedial periolivary nucleus. The physiological data are consistent with anatomic data derived from HRP injections in the MSO (Covey et al. 1991; Grothe 1990) and the inferior colliculus (Ross and Pollak 1989). Predominantly monaural responses within the medial part of the SOC have been described only for the ventral MSO in the rufous horseshoe bat, Rhinolophus rouxi (Casseday et al. 1988). Physiological and anatomic data on other species of bats indicate that this picture may not be typical for all microchiroptera. The MSOs in the molossid bat Molossus ater (Harnischfeger et al. 1985) and in the free-tailed- bat Tadarida bra- 

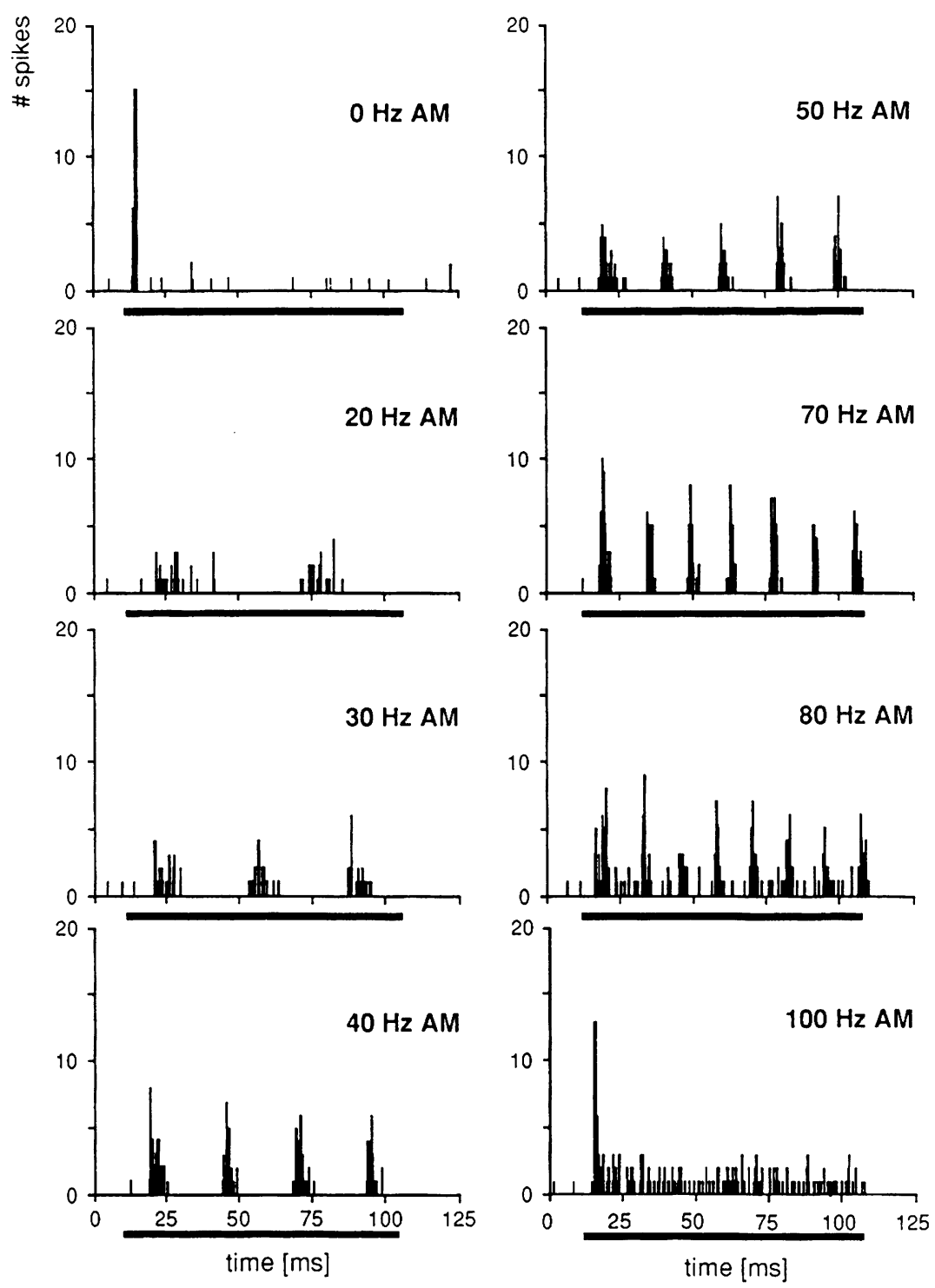

siliensis (W. Siefer and M. Vater, unpublished results; Grothe et al. 1994) are described as binaural.

\section{Response patterns}

The second major respect in which the MSO in the mustached bat differs from those of other mammals is the predominance of phasic response patterns $(85 \%)$. In all previous studies MSO neurons were reported to respond with a sustained discharge pattern: dogs (Goldberg and Brown 1969), cats (Caird and Klinke 1983; Guinan et al. 1972), the molossid bat (Harnischfeger et al. 1985), the rufous horseshoe bat (Casseday et al. 1988), and the little brown bat (Myotis lucifugus; Jen 1978).

\section{Functional role of the MNTB-MSO projection}

The most obvious connectional characteristic of the mustached bat's MSO is the prominent projection from the MNTB and the reduction of the ipsilateral input from the CN (Covey et al. 1991; Grothe 1990; Grothe et al. 1992). Other mammals are also known to have projections from the MNTB to the MSO. These take the form of collaterals from the MNTB-LSO projection (Cant and Hyson 1992; Casseday et al. 1988; Kiss and Majorossy 1983; Kuwabara and Zook 1992; Spangler et al. 1985). Since in these animals the inhibition does not lead to phasic response patterns (see above) it does not seem to be as strongly developed as it is in the mustached bat. Additionally, there are recent results from in vitro studies suggesting that synaptic inhibition in the MSO of gerbils and guinea pigs is level dependent and is sufficient to block action potentials at high stimulus intensities only (Grothe and Sanes 1992, 1993; Smith and Banks 1992). The principal neurons within the MNTB are glycinergic and this nucleus is thought to have a higher concentration of glycine than any other structure in the mammalian CNS (Caspary and Finlayson 1991; Glendenning and Baker 1988; Wenthold and Hunter 1990). Numerous glycinergic synapses are present in the LSO and also in the MSO (Glendenning and Baker 1988; Saint Marie et al. 1989; Wenthold et al. 1987; M. Vater, unpublished data). Moore and Caspary (1983) demonstrated that in chinchilla LSO they could block contralateral inhibition by delivering the glycine antagonist strych- 

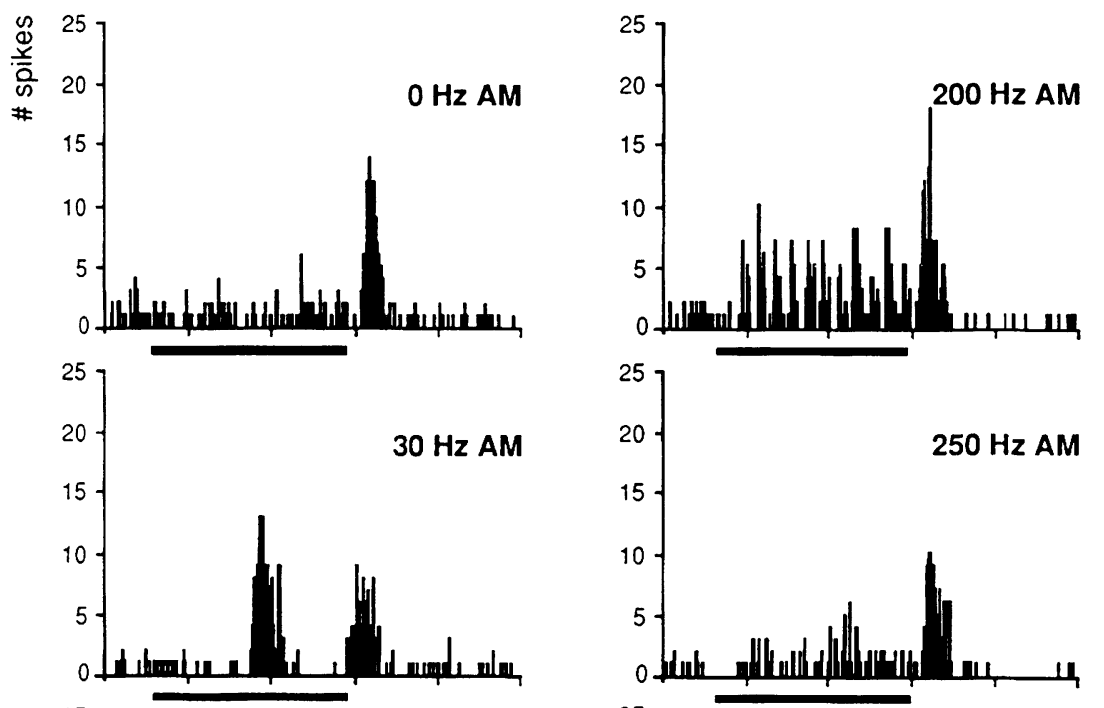

FIG. 11. Response of a MSO neuron with an OFF discharge to different SAM frequencies and to an unmodulated tone burst $(0 \mathrm{~Hz}$; top left PSTH; $\mathrm{BF}$ and carrier frequency: $35 \mathrm{kHz}$ ). SAM frequencies were varied from 30 to $300 \mathrm{~Hz}$. This neuron responded to each modulation cycle at 30 and $100 \mathrm{~Hz}$. At $200-\mathrm{Hz}$ SAM frequency the response to the individual modulations decreased and the final OFF response became much more prominent. At higher SAM frequencies $(250$ and $300 \mathrm{~Hz}$ ) only the final OFF response remained. Ordinate: total number
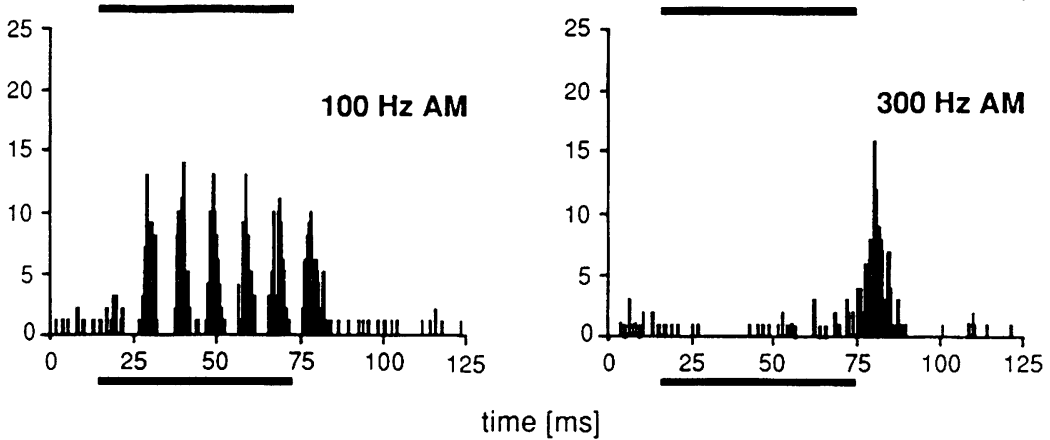
of spikes to 60 stimulus repetitions. Binwidth is $0.5 \mathrm{~ms}$.

nine. In other mammals the function of the glycinergic projection to the MSO is undefined. However, there is neurophysiological evidence of bilateral inhibitory input to MSO neurons in dogs, cats, gerbils, and guinea pigs (Goldberg and Brown 1969; Grothe and Sanes 1992, 1993; Smith and Banks 1992; Yin and Chan 1990).

Moreover, there is also evidence from in vivo studies in cats and dogs and from an in vitro study in gerbils that



FIG. 12. The filter characteristics of SAM responses for the 2 neurons shown in Fig. $10(A)$ and Fig. $11(B)$, expressed as spikes per cycle normalized to the best response per cycle (- - ) and vector strength (-). $A$ : typical band-pass filter characteristic (best response between 65 and 80 $\mathrm{Hz}$ ). $B$ : low-pass filter characteristic (best responses $\leq 150 \mathrm{~Hz}$ ). Ordinate: ratio between the averaged number of spikes per SAM cycle at a given SAM frequency and the averaged number of spikes per SAM cycle at the best SAM frequency. inhibition influences the timing or the ability to code ITDs in some MSO neurons. Some phase-locking EE neurons in cats and dogs possess inhibitory sidebands causing an outof-phase inhibition if the interaural phases are not coincident. The discharge activity in these situations is less than that evoked by monaural stimulation alone and often less than the spontaneous activity of the neuron. Additionally, some MSO neurons in cats and dogs exhibit nonmonotonic rate-level functions (Goldberg and Brown 1969; Yin and Chan 1990). These inhibitory inputs are not expected in the coincidence detection model of a MSO that should receive excitatory inputs only (e.g., Colburn et al. 1990; Jeffress 1948). Intracellular recordings in gerbil brain slice preparations revealed a level-dependent glycinergic inhibition that influences the probability of a second spike occurring in interaural time delay experiments (Grothe and Sanes 1994). The function of these inhibitory influences is still not understood. However, the effects depend on the timing of the inputs, and therefore mechanisms might exist comparable with the MNTB-MSO interaction presented here.

In the MSO of the mustached bat, the glycinergic input derived from the ipsilateral MNTB appears to reduce the sustained excitatory input from the contralateral $\mathrm{CN}$ to a phasic discharge. The neuropharmacological experiments and the two-tone experiments described in this study indicate that the inhibitory input must be sustained for the duration of stimulation. Because of differences in the latencies of the converging excitatory and inhibitory projections to the MSO, the resulting response types encompass on as well as rebound ofF patterns. If the inhibitory inputs are 

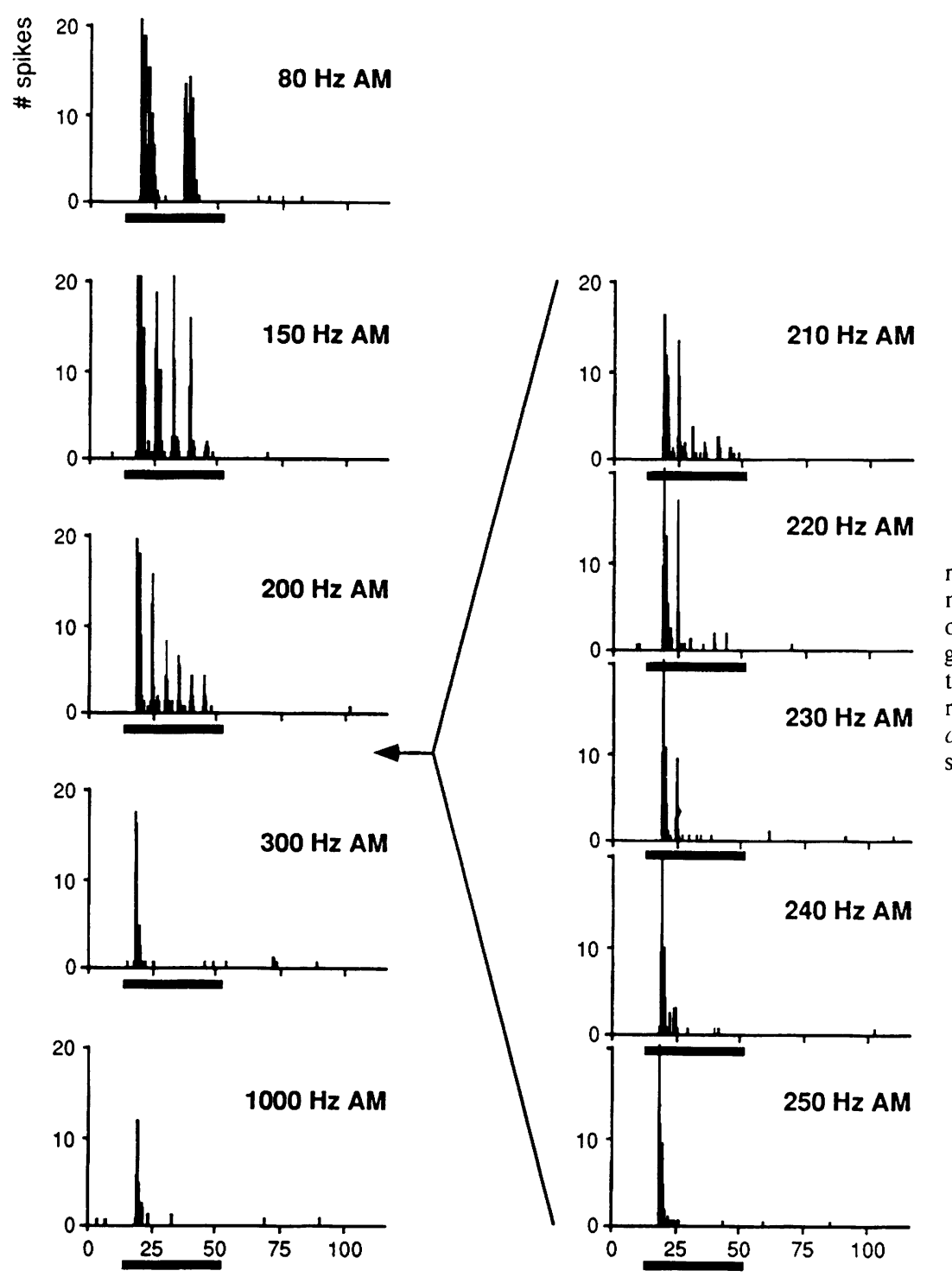

FIG. 13. Determination of the upper filter limit in a neuron with a low-pass filter characteristic (BF: $61.2 \mathrm{kHz}$ ). This neuron responded to each modulation cycle at frequencies of $\leq 200 \mathrm{~Hz}$, even though the overall response decreased progressively from cycle to cycle throughout the stimulus duration. Between 200- and $250-\mathrm{Hz}$ SAM frequency, the neuron's response was reduced to only 1 ON discharge. Right column: reduction in $10-\mathrm{Hz}$ steps. Ordinate: total number of spikes to 60 stimulus repetitions. Binwidth is $0.5 \mathrm{~ms}$.

$230 \mathrm{~Hz}$ AM

delayed by $\leq 5 \mathrm{~ms}$ relative to the excitatory input, oN responses result, whereas a simultaneous or earlier inhibition creates a rebound ofF response.

Therefore, in the mustached bat as well as in other mammals, the exact timing of different inputs to the MSO is important. In most mammals, the precise timing of binaural excitatory inputs is necessary for analysis of IPDs and ITDs; in the mustached bat, the important time relationship appears to be that of one excitatory and one inhibitory input, both from the contralateral ear.

\section{ON-OFF neurons within the $61-\mathrm{kHz}$ region}

The change in response patterns from phasic to sustained discharges in the presence of strychnine was observed in all MSO neurons except those exhibiting ON-OFF discharges. This response property is predominantly represented in the $61-\mathrm{kHz}$ region in the medial limb of the MSO (Covey et al. 1991). The few ON-OFF cells investigated were insensitive to glycine and strychnine. This supports the interpretation that ON-OFF response pattern are created at lower levels of the auditory system. The appearance of these response patterns is a well-known phenomenon of the peripheral auditory system in the mustached bat (Kössl and Vater 1990; Suga et al. 1975). Covey et al. (1991) described the frequency dependence of these response patterns in the mustached bat's MSO in detail. In their experiments, neurons with ON-OFF response properties also seem to be different from other neurons within the MSO. Only these neurons exhibit different response patterns for different frequencies. In the present study those cells were the only ones that exhibited nonmonotonic rate-level functions. Additionally, the only MSO neuron that did not synchronize its discharge to SAM signals was an ON-OFF neuron with a BF of $\sim 61$ $\mathrm{kHz}$. This finding may be related to observations by Lesser et al. (1990), who reported that in the dorsoposterior division of the inferior colliculus of the mustached bat there is a "small but significant population" of neurons that exhibits ON-OFF response properties and that does not respond to SAM tone bursts. These neurons are unlike other neurons within the $61-\mathrm{kHz}$ region that do respond to SAM signals. These findings support the idea that ON-OFF neurons per- 


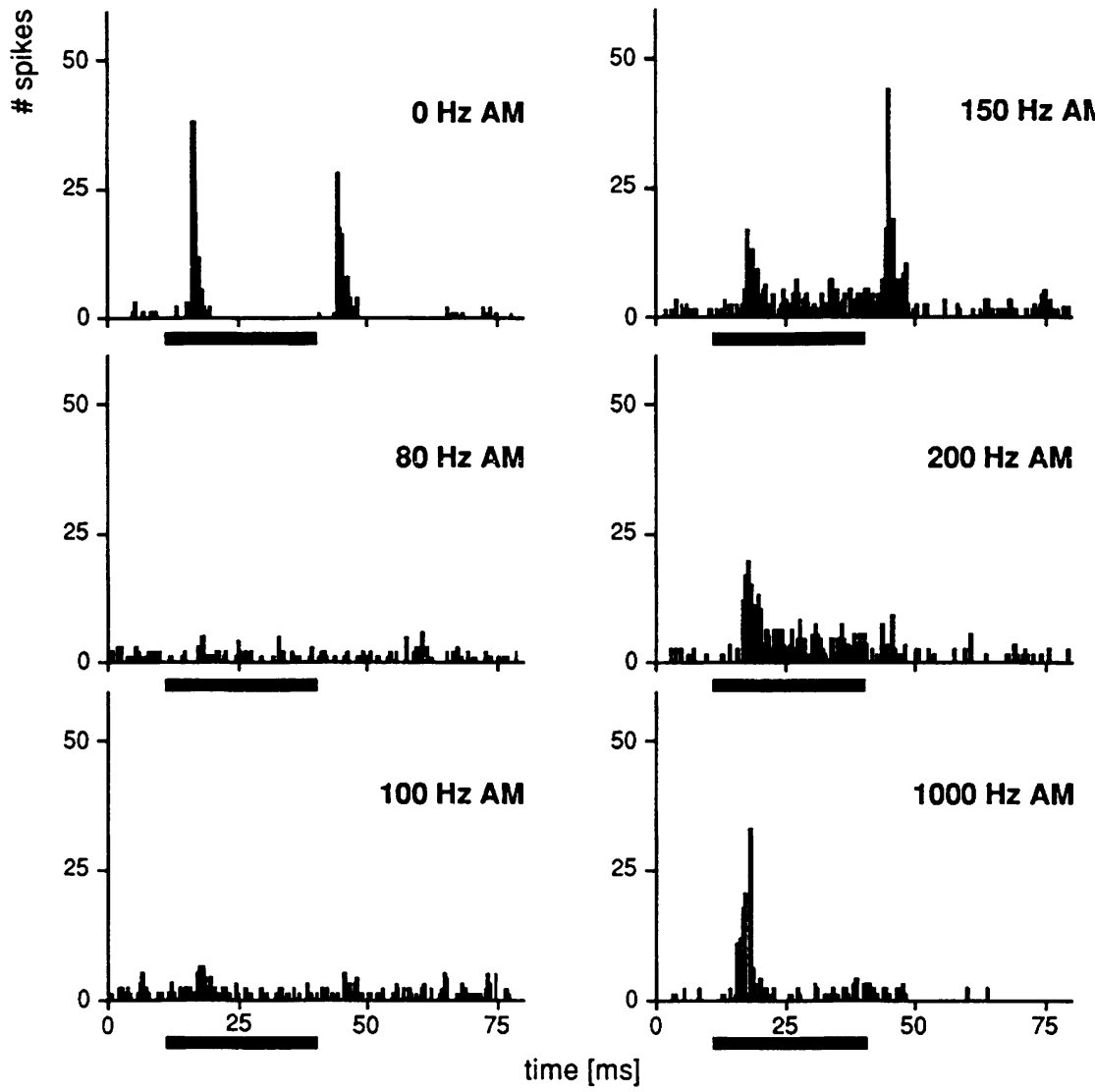

FIG. 14. Example of the response patterns of a neuron with a $\mathrm{BF}$ of $60.9 \mathrm{kHz}$, close to the $\mathrm{CF}_{2}$. This neuron responded to pure tones with an ON-OFF discharge. It did not respond to SAM frequencies $<100$ $\mathrm{Hz}$. At $150 \mathrm{~Hz}$ it discharged with an ON-OFF pattern. At higher SAM frequencies the response changed to a sustained $(200 \mathrm{~Hz})$ and finally an $\mathrm{ON}$ response $(1,000$ $\mathrm{Hz}$ ). The neuron's discharge never phase-locked to the SAM stimulus. Ordinate: total number of spikes to 60 stimulus repetitions. Binwidth is $0.5 \mathrm{~ms}$. form a unique function within the auditory system of the mustached bat (Covey et al. 1991; Lesser et al. 1990).

\section{SAM filter mechanism in MSO neurons}

The interaction of monaural excitation and inhibition within the MSO of the mustached bat provides a mechanism for further processing of AM signals. The results described above suggest that the response activity of MSO neurons is governed by the relative timing of excitatory and inhibitory inputs. Depending on the relative timing of the two inputs there exists a distinct modulation frequency at which the inhibition elicited by one cycle of the SAM signal begins to overlap with the excitation of the next modulation cycle, or, in neurons with rebound off discharges, the inhibition from one cycle overlaps the rebound response of the previous cycle. Thus the discharge of MSO neurons should depend on the modulation frequency of SAM signals: the present results show that MSO neurons do exhibit selectivity for SAM rate. Figure 17 illustrates the hypothesis that SAM rate selectivity in the MSO of the mustached bat arises through interaction of excitation and inhibition and that selectivity for SAM signals depends on the relative timing between the two inputs. As an example a MSO neuron is shown that discharges with a phasic oN response and a delay of inhibition of $\sim 3 \mathrm{~ms}$. At modulation frequencies of 55 and $110 \mathrm{~Hz}$ (top and middle panels) the inhibition does not completely overlap with the excitation, and the neuron responds phasically during the period when only excitation is present. In the bottom panel the modulation frequency is $333 \mathrm{~Hz}$. In this case the inhibition exactly overlaps the exci- tation caused by the following cycle. The neuron would only discharge to the first cycle of modulation. The relation between the filter cutoff and the delay of inhibition should be: filter cutoff $=1 /$ delay $(\mathrm{s})$. For a neuron with 5-ms delay of the inhibition the cutoff would occur at $555 \mathrm{~Hz}$ AM frequency and for delays of $<3 \mathrm{~ms}$ at frequencies lower than $333 \mathrm{~Hz}$. The weak temporal summation of inhibition that was observed in some neurons would smooth the way a neuron's response changes as SAM frequency passes across the cutoff frequency.

In agreement with this model, the neuropharmacological experiments with strychnine showed that the upper filter limit is created within the MSO itself through the monaural interaction of the excitatory input from $A V C N$ with the glycinergic inhibitory input from MNTB. The upper filter limit for SAM signals is determined by the relative timing of the two inputs, which differs among neurons: longer delays of the inhibition produce lower SAM filter limits, whereas shorter delays of the inhibitory input produce higher SAM filter limits. When inhibition is antagonized by strychnine, the upper SAM limits shift to values present in the sustained excitatory input from AVCN.

In contrast, the lower cutoff in band-pass neurons is independent of inhibitory inputs. Additionally, the way in which the response to SAM frequencies below the lower cutoff frequency decreases is different from the way in which the response decreases above the upper SAM cutoff frequency. At high SAM frequencies the reduction of spikes is due to the overlap of excitation and inhibition evoked by different cycles of the SAM stimulus and only the response to the first cycle in ON neurons and the last cycle in OFF 



FIG. 15. Spontaneously active off neuron that did not follow SAM frequencies $>200 \mathrm{~Hz}$. At $250-\mathrm{Hz}$ SAM frequency (top histogram) there was only one OFF discharge per stimulus. When strychnine was applied, a SAM phase-locked response could be evoked. After 2-min delivery of strychnine each SAM cycle produced a discharge. A higher concentration of strychnine led to a sustained discharge. Ordinate: total number of spikes to 60 stimulus repetitions. Binwidth is $0.5 \mathrm{~ms}$.

neurons remains. The reduction in spikes at low SAM frequencies in band-pass neurons is due to a general decrease in the number of spikes per AM cycle, including the first or last cycle. The lower cutoff rate seems to depend on the steepness of the stimulus rise time (Grothe, unpublished results). A comparable effect is shown for neurons of the ventral nucleus of the lateral lemniscus in the mustached bat that phase-lock only at high SAM frequencies. In these neurons the steepness of rise time appears also to be responsible for the high-pass filter characteristic of these neurons (O'Neill et al. 1992).

\section{Behavioral relevance of SAM signal processing}

The MSO in the mustached bat $P$. parnellii differs in several respects from the MSO in all other mammals that have been investigated. It seems to represent an adaptation to special evolutionary constraints (Casseday et al. 1988; Covey et al. 1991; Grothe 1990; Grothe et al. 1994), possibly related to the special CF-FM echolocation call of the mustached bat and the bat's ability to detect fluttering targets within a cluttered environment by analyzing frequency and amplitude modulations within the CF part of the echo (Goldman and Henson 1977; Henson et al. 1987).

The finding that MSO neurons exhibit band-pass and low-pass filter characteristics for amplitude modulations suggests that the MSO represents a stage in the processing of temporal information. In general, it is known that neurons in lower auditory nuclei are less selective for SAM signals than neurons at higher levels. Neurons in the $\mathrm{CN}$ synchronize their discharges for SAM frequencies $\leq 1,000 \mathrm{~Hz}$ (Frisina 1984, 1990a,b; Moller 1974-1976; Vater 1982; for review to AM coding see Langner 1992), whereas neurons of the inferior colliculus commonly exhibit upper limits $<400$ $\mathrm{Hz}$ (Pollak and Schuller 1981; Reimer 1987). The filter characteristics in the auditory cortex are even more limited (Schreiner and Urbas 1986, 1988). Thus it appears that structures at several levels in the ascending auditory pathways filter periodic amplitude modulations. The MSO in the mustached bat is quite different from the MSO in other mammals with regard to its connections and physiology. Thus the question arises of whether this additional AM processing has special behavioral relevance for the mustached bat.

The CF component of echoes reflected from flying insects contains information about Doppler shift from which relative velocity and flight direction of an insect can be derived (Schnitzler 1970). The echoes of the CF also contain different interference patterns seen as frequency and amplitude modulations (Henson et al. 1987). These periodic modulations within the CF echo yield information about the size and shape of insects (Kober and Schnitzler 1990). CF-FM bats are able to identify and recognize different species of insects on the basis of echoes with amplitude as well as frequency modulations (von der Emde 1990). Additionally it has been shown that these animals are attracted to fluttering targets, whether flying insects or just an insect-



FIG. 16. The response of an MSO neuron to different SAM frequencies. This neuron responded to a nonmodulated tone with a broad oN response ( $>5 \mathrm{~ms}$ ) and a weak sustained response. Probably as a result of the incomplete inhibition, the neuron's response to SAM frequencies $>300 \mathrm{~Hz}$ was reduced, but not completely inhibited. However, in the presence of strychnine the neuron was able to follow SAM frequencies very precisely up to $\geq 800 \mathrm{~Hz}$. $A$ : ratio between the averaged number of spikes per SAM cycle at a given SAM frequency and the averaged number of spikes per SAM cycle at the best SAM frequency before (control) and during the presence of strychnine. $B$ : corresponding vector strength functions. 

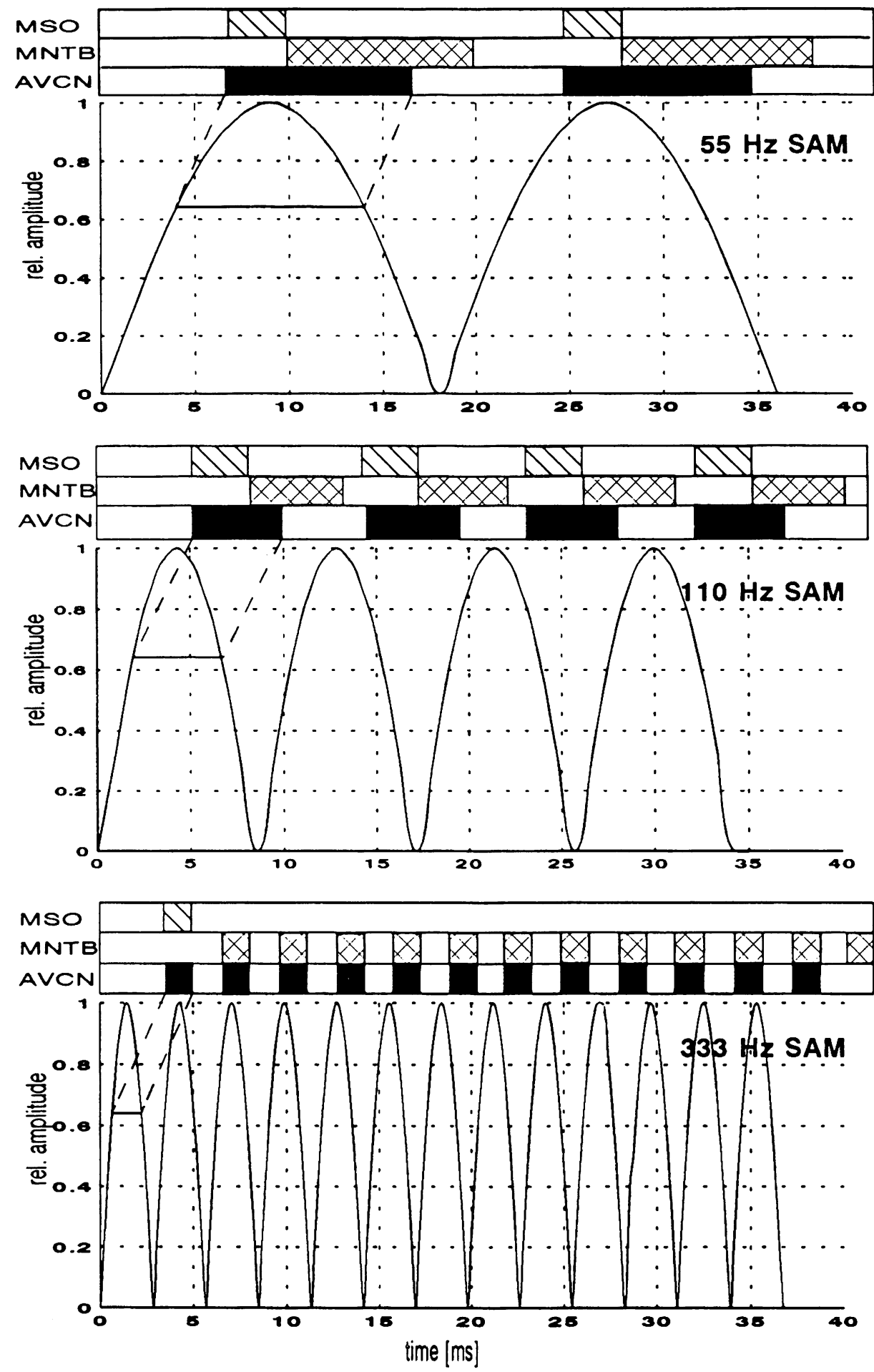

FIG. 17. Schematic drawing of the response of a hypothetical neuron within the mustached bat's MSO to different AM rates. The latency of the excitatory input is assumed to be $3 \mathrm{~ms}$ and the latency of the inhibitory input is assumed to be $6 \mathrm{~ms}$ relative to the stimulus onset. Vertical line within the 1st AM cycle: threshold for response (relative 0.63 ). Black bars above the AM curve: timing and duration of the excitatory input from the anteroventral cochlear nucleus (AVCN). Cross-hatched bars: inhibitory medial nucleus of trapezoid body (MNTB) input. Striped bars: MSO neuron's resulting response. At 55and $110-\mathrm{Hz}$ SAM frequency the neuron responds to each cycle. If the duration of 1 cycle is the same as or shorter than the relative delay of inhibition, the period of excitation to the 2nd cycle overlaps the period of inhibition due to the 1st cycle $(333 \mathrm{~Hz})$. The result is that there is only 1 oN response to the entire stimulus, and the cell does not phase-lock to the SAM cycle. Thus this hypothetical neuron shows a low-pass filter characteristic for periodic amplitude modulations with an upper cutoff of $\sim 333 \mathrm{~Hz}$. simulating propeller. Furthermore, the mustached bat can recognize insects as palatable or nonpalatable on the basis of their patterns of wingbeats (Goldman and Henson 1977).

\section{Conclusions}

The mustached bat may rely to a large extent on processing the temporal structure of acoustic stimuli, particularly modulations within echoes reflected from fluttering targets.
Thus this bat might have experienced evolutionary constraints to improve its ability to analyze amplitude modulations and periodicity information. In the MSO of the mustached bat, the temporal interaction of excitation and inhibition produces filters for temporal patterns and determines the range of amplitude modulation rates to which a neuron will respond. In a binaural MSO the interaural interactions would mask the specificity of such AM filters, shifting the filter properties as a function of the temporal disparities between binaural synaptic inputs. Temporal dis- 
parities in the binaural MSO would be caused by ITDs and, especially in the case of high-frequency sounds, by time-intensity trading of interaural intensity differences (Caird and Klinke 1983; Goldberg and Brown 1969; Kitzes et al. 1980; Pollak 1988; Yin et al. 1985). The reduction of ipsilateral excitatory projections in the mustached bat could improve the characteristics and stability of the AM filters and allow MSO neurons to encode certain features of an acoustic stimulus independent of the position of the sound source in space. Thus the MSO in the mustached bat may be adapted particularly to perform AM filtering that is important for detecting wing- beating prey.

These results support the idea of the SOC, and especially $\mathrm{MSO}$, as a region with high evolutionary plasticity and special adaptations in different mammals.

I thank Dr. G. Neuweiler for support and critical discussions, and Drs. T. Park, G. D. Pollak, and D. H. Sanes for comments on the manuscript and helpful suggestions. I especially thank Dr. E. Covey for help with the author's English and many helpful comments and Martin Baumann for expert design of the data acquisition software for on- and off-line processing.

This work was supported by the Deutsche Forschungsgemeinschaft (SFB 204).

Received 29 March 1993: accepted in final form 21 October 1993.

\section{REFERENCES}

Boudreau. J. C. AND Tsuchitani, C. Binaural interaction in the cat superior olive S-segment. J. Neurophysiol. 31: 442-454, 1968.

Brownell, W. E., Manis, P. B., AND RITZ, L. A. Ipsilateral inhibitory responses in the cat lateral superior olive. Brain Res. 177: 189-193, 1979.

CAIRD, D. AND Klinke, R. Processing of binaural stimuli by cat superior olivary complex neurons. Exp. Brain Res. 52: 385-399, 1983.

CANT, N. B. Projections to the lateral and medial superior olivary nuclei from the spherical and globular bushy cells of the anteroventral cochlear nucleus. In: Netrobiology of Hearing: The Central Sistem, edited by R. A. Altschuler, R. P. Bobbin, B. M. Clopton, and D. W. Hoffman. New York: Raven, 1991, p. 99-119.

Cant, N. B. and Casseday, J. H. Projections from the anteroventral cochlear nucleus to the lateral and medial superior olivary nuclei. $J$. Comp. Neurol. 247: 457-476, 1986.

CANT, N. B. AND Hyson, R. L. Projections from the lateral nucleus of the trapezoid body to the medial olivary nucleus in the gerbil. Hear. Res. 58: 26-34, 1992.

CASPARY, D. M. AND FInLAYSON, P. G. Superior olivary complex: functional neuropharmacology of the principal cells. In: Neurobiology of Hearing: The Central System, edited by R. A. Altschuler, R. P. Bobbin, B. M. Clopton, and D. W. Hoffman. New York: Raven, 1991, p. 141161.

Casseday, J. H., Covey, E., ANd Vater, M. Connections of the superior olivary complex in the rufous horseshoe bat, Rhinolophus rouxi. $J$. Comp. Neurol. 278: 313-329. 1988.

Colburn, H. S., Han, Y., and Culotta, C. P. Coincidence model of MSO responses. Hear. Res. 49: 335-346, 1990.

COVEY, E., VATER, M., AND CASSEDAY, J. H. Binaural properties of single units in the superior olivary complex of the mustached bat. J. Neurophysiol. 66: 1080-1094, 1991.

VON DER EMDE. G. Classification of insects by echolocating greater horseshoe bats. J. Comp. Physiol. 167: 423-430, 1990.

FENG, A. S. AND VATER, M. Functional organization of the cochlear nucleus of rufous horseshoe bats (Rhinolophus rouxi): frequencies and internal connections are arranged in slabs. J. Comp. Neurol. 235: 529$553,1985$.

Frisina, R. D., SMith, R. L., and Chamberlain, S. C. Encoding of amplitude modulation in the gerbil cochlear nucleus. I. A hierarchy of enhancement. Hear. Res. 44: 99-122, 1990a.

Frisina, R. D., SMith, R. L., AND Chamberlain, S. C. Encoding of amplitude modulation in the gerbil cochlear nucleus. II. Possible neural mechanisms. Hear. Res. 44: 123-142, 1990b.
Frisina, R. D., Smith, R. L., and Chamberlain, S. C. Responses to amplitude modulation in the cochlear nucleus: a hierarchy of enhancement (Abstract). J. Acoust. Soc. Am. 75: 68, 1984.

GLENDENNING, K. K. AND BAKER, B. N. Neuroanatomical distribution of receptors for three potential inhibitory neurotransmitters in the brainstem auditory nuclei of the cat. J. Comp. Neurol. 275: 288-308, 1988.

GoldBerg, J. M. AND BRowN, P. B. Functional organization of the dog superior olivary complex: an anatomical and electrophysiological study. J. Neurophysiol. 31: 639-656, 1968.

GOLDBERG, J. M. AND BROWN, P. B. Response of binaural neurons of the dog superior olivary complex to dichotic tonal stimuli: some physiological mechanisms of sound localization. J. Neurophysiol. 32: 613-636, 1969.

Goldman, L. J. and Henson, O. W., JR. Prey recognition and selection by the constant frequency bat, Pteronotus p. parnellii. Behav. Ecol. Sociobiol. 2: 411-419, 1977.

GROTHE, B. Versuche einer Definition des medialen Kernes des oberen Olivenkomplexes bei der Neuweltfledermaus Pteronotus parnellii ( $\mathrm{PhD}$ dissertation). Munich, Germany: Ludwig-Maximilians-Universität München, 1990.

GROTHE, B. AND SANES, D. H. In vitro analysis of synaptic integration in the medial superior olive. Soc. Neurosci. Abstr. 18: 151, 1992.

Grothe, B. AND SANES, D. H. Bilateral inhibition by glycinergic afferents in the medial superior olive. J. Neurophysiol. 69: 1192-1196, 1993.

Grothe, B., AND SANES, D. H. Inhibition influences the temporal response properties of gerbil medial superior olive neurons: an in-vitro study. J. Neurosci. In press.

Grothe, B., Schweizer, H., Pollak, G., Schuller, G., and RoseMANN, C. Anatomy and projection patterns of the superior olivary complex in the Mexican free-tailed-bat, Tadarida brasiliensis mexicana. $J$. Comp. Neurol. In press.

Grothe, B., Vater, M., Casseday, J. H., and Covey, E. Monaural interaction of excitation and inhibition in the medial superior olive of the mustached bat: an adaptation for biosonar. Proc. Natl. Acad. Sci. USA 89: 5108-5112, 1992.

GuinaN, J. J., Guinan, S. S., AND Norris, B. E. Single auditory units in the superior olivary complex. I. Responses to sounds and classification based on physiological properties. Int. J. Neurosci. 4: 101-120, 1972.

HaRnischfeger, G., NeuWeILer, G., AND SCHLEgel, P. Interaural time and intensity coding in superior olivary complex and inferior colliculus of the echolocating bat Molossus ater. J. Neurophysiol. 53: 89-109, 1985.

HARRISON, J. M. AND IRVING, R. Visual and nonvisual auditory systems in mammals. Science Wash. DC 154: 738-743, 1966.

Henson, O. W., JR., Bishop, A., Keating, A., Kobler, J., Henson, M., Wilson, B., AND HANSEN, R. Biosonar imaging of insects by Pteronotus p. parnellii, the mustached bat. Natl. Geogr. Res. 3: 82-101, 1987.

IRVING, R. AND HARRISON, J. M. The superior olivary complex and audition: a comparative study. J. Comp. Neurol. 130: 77-86, 1967.

Jefreress, L. A. A place theory of sound localization. J. Comp. Physiol. Psychol. 41: 35-39, 1948.

JEN, P. H.-S. Electrophysiological properties of auditory neurons in the superior olivary complex of echolocating bats. J. Comp. Physicl. 128: 47-56, 1978

KISS, A. AND MAJOROSSY, K. Neuron morphology and synaptic architecture in the medial superior olivary nucleus. Light- and electron microscope studies in the cat. Exp. Brain Res. 52: 315-327, 1983.

Kitzes, L. M., WREGE, K. S., AND Cassady, J. M. Patterns of response of cortical cells to binaural stimulation. J. Comp. Neurol. 192: 455-472, 1980.

KOBER, R. AND SCHNITZLER, H.-U. Information in sonar echoes of fluttering insects available for echolocating bats. J. Acoust. Soc. Am. 87: 882$896,1990$.

KöSSL, M. AND VATER, M. The cochlear frequency map of the bat Pteronotus parnellii. J. Comp. Physiol. 157: 687-697, 1985.

KöSSL, M. AND VATER, M. Tonotopic organization of the cochlear nucleus of the mustache bat, Pteronotus parnellii. J. Comp. Physiol. 166: 695-709, 1990.

Kuwabara, N. AND Zook, J. M. Projections to the medial superior olive from the medial and lateral nuclei of the trapezoid body in rodents and bats. J. Comp. Neurol. 324: 522-538, 1992.

LANGNeR, G. Periodicity coding in the auditory system. Hear. Res. 60: 115-142, 1992.

Lesser, H. D.. O’Neill, W. E., Frisina, R. D., and Emerson, R. C. 
ON-OFF units in the mustached bat inferior colliculus are selective for transient resembling "acoustic glint" from fluttering insect targets. Exp. Brain Res. 82: 137-148, 1990.

MASTERTON, R. B. AND DiAmOND, I. T. Medial superior olive and sound localization. Science Wash. DC 155: 1696-1697, 1967.

MASTERTON, R. B. AND IMIG. T. J. Neural mechanisms for sound localization. Annu. Rev. Physiol. 46: 275-287, 1984.

MOLLER, A. R. Responses of units in the cochlear nucleus to sinusoidally amplitude-modulated sounds. J. Exp. Neurol. 45: 104-117, 1974.

MOLleR, A. R. Dynamic properties of excitation and inhibition in the cochlear nucleus. Acta. Physiol. Scand. 93: 442-454, 1975.

MOLLER, A. R. Dynamic properties of excitation and two-tone inhibition in the cochlear nucleus studied using amplitude modulated tones. Exp. Brain Res. 25: 307-321, 1976.

MOORE, M. J. AND CASPAKY, D. M. Strychnine blocks binaural inhibition in lateral superior olivary complex. J. Neurosci. 3: 237-242, 1983.

O'NeIll, W. E., HOLT, J. R., AND GORDON, M. Responses of neurons in the intermediate and ventral nuclei of the lateral lemniscus of the mustached bat to sinusoidal and pseudorandom amplitude modulations. Abstr. ARO Midwinter Mtg. 15: 418, 1992.

POLLAK, G. D. Time is traded for intensity in the bat's auditory system. Hear. Res. 36: 107-124, 1988.

Pollak, G. and Casseday, J. H. The Neural Basis of Echolocation in Bats. Berlin: Springer-Verlag, 1990.

POllak, G. D. AND SCHuller, G. Tonotopic organisation and encoding features of single units in the inferior colliculus of horseshoe bats: functional implications for prey identification. J. Neurophysiol. 45: 208226, 1981.

REIMER, K. Coding of sinusoidally amplitude modulated acoustic stimuli in the inferior colliculus of the rufous horseshoe bat, Rhinolophus rouxi. J. Comp. Physiol. 161: 305-313, 1987.

Ross, L. S. AND POLLAK, G. D. Differential ascending projections to monaural regions in the $60 \mathrm{kHz}$ contour of the mustache bat's inferior colliculus. J. Neurosci. 9: 2819-2834, 1989.

Saint Marie, R. L., Ostapoff, E. M., Morest, D. K., and Wenthold, R. J. Glycine-immunoreactive projection of the cat lateral superior olive: possible role in midbrain ear dominance. J. Comp. Neurol. 279: 382-396, 1989.

SANES. D. H. An in vitro analysis of sound localization mechanisms in the gerbil lateral superior olive. J. Neurosci. 10: 3494-3506, 1990.

SCHLEGEL, P. Calibrated earphones for the echolocating bat, Rhinolophus ferrumequinum. J. Comp. Physiol. 118: 353-356, 1977.

SCHNITZLER, H.-U. Echoortung bei der Fledermaus Chilonvcteris rubiginosa. Z. Vgl. Physiol. 68: 25-38, 1970.

SCHREINER. C. E. AND URBAS, J. V. Representation of amplitude modulation in the auditory cortex of the cat. II. Comparison between cortical fields. Hear. Res. 32: 49-64, 1986.

SCHREINER, C. E. AND URBAS, J. V. Representation of amplitude modulation in the auditory cortex of the cat. I. The anterior auditory field (AAF). Hear. Res. 21: 227-241, 1988.
SMITH, P. H. AND BANKS, M. I. Intracellular recordings from neurobiotinlabeled principal cells in the brain slice of the guinea pig. Soc. Neurosci. Abstr. 18: 382, 1992.

SPANGler, K. M., WarR, W. B., AND Henkel, C. K. The projections of principal cells of the medial nucleus of the trapezoid body in the cat. $J$. Comp. Neurol. 238: 249-261, 1985.

SuGA, N. Principles of auditory information-processing derived from neuroethology. J. Exp. Biol. 146: 277-286, 1989.

Suga, N., Simmons, J. A., AND Jen, P. H.-S. Peripheral specialization for fine frequency analysis of doppler-shifted echos in the "CF-FM" bat, Pteronotus parnellii. J. Exp. Biol. 63: 161-192, 1975.

TsUCHITANI, C. Functional organization of lateral cell groups of cat superior olivary complex. J. Neurophysiol. 40: 297-318, 1977.

TsUCHITANI, C. AND JOHNSON, D. H. Binaural cues and signal processing in the superior olivary complex. In: Neurobiology of Hearing: the Central System, edited by R. A. Altschuler, R. P. Bobbin, B. M. Clopton, and D. W. Hoffman. New York: Raven, 1991, p. 163-193.

VATER, M. Single unit responses in cochlear nucleus of horseshoe bats to sinusoidal frequency and amplitude modulated signals. J. Comp. Physiol. 149: 369-388, 1982.

WARR, W. B. Parallel ascending pathways from the cochlear nucleus: neuroanatomical evidence of functional specialization. Contrib. Sens. Physiol. 7: 1-38, 1982.

Wenthold, L. P., Huie, D., Altschuler, R. A., ANd Reeks, K. A. Glycine immunoreactivity localized in the cochlear nucleus and the superior olivary complex. J. Neurosci. 22: 897-912, 1987.

WENTHOLD, R. J. AND HUNTER, C. Immunohistochemistry of glycine and glycine receptors in the central auditory system. In: Glycine neurotransmission, edited by O. P. Ottersen and F. Strom-Mathisen. West Sussex, UK: Wiley, 1990, p. 391-416.

YIN, T. C. T. AND CHAN, J. C. K. Interaural time sensitivity in medial superior olive of cat. J. Neurophysiol. 64: 465-488, 1990.

YIN, T. C. T. HIRSCH, J. A., AND CHAN, J. C. K. Response of neurons in the cat's superior colliculus to acoustic stimuli. II. A model of interaural intensity sensitivity. J. Neurophysiol. 53: 746-758, 1985.

ZOOK, J. M. AND CASSEDAY, J. H. Cytoarchitecture of auditory system in lower brainstem of the mustache bat, Pteronotus parnellii. J. Comp. Neurol. 207: 1-13, 1982a.

ZOOK, J. M. AND CASSEDAY, J. H. Origin of ascending projections to inferior colliculus in the mustache bat, Pteronotus parnellii. J. Comp. Neurol. 207: 14-28, 1982b.

ZOOK, J. M. AND CASSEDAY, J. H. Projections from the cochlear nuclei in the mustache bat. Pteronotus parnellii. J. Comp. Neurol. 237: 307-329, 1985.

ZOOK, J. M. AND DICAPRIO, R. A. Intracellular labelling of afferents to the lateral superior olive in the bat, Eptesicus fuscus. Hear. Res. 34: 14-148, 1988.

ZOOK, J. M. AND LEAKE, P. A. Connections and frequency representation in the auditory brainstem of the mustache bat, Pteronotus parnellii. $J$. Comp. Neurol. 290: 243-261, 1989. 